\title{
Marital Conflict and Children's Adjustment: A Cognitive-Contextual Framework
}

\author{
John H. Grych and Frank D. Fincham \\ University of Illinois
}

\begin{abstract}
Marital problems have been related to numerous indexes of maladjustment in children. Although several parameters of this association have been identified, the process by which exposure to interparental conflict gives rise to adjustment problems in children is largely unexplored. Research on the link between marital conflict and child maladjustment therefore is critically evaluated, and a framework is presented that organizes existing studies and suggests directions for future research on processes that may account for the association. According to the framework, the impact of marital conflict is mediated by children's understanding of the conflict, which is shaped by contextual, cognitive, and developmental factors. The implications of the framework for children's adjustment are discussed.
\end{abstract}

Marital discord has been associated with a number of indexes of maladjustment in children, including aggression, conduct disorders, and anxiety (Emery, 1982, 1988). Research on the effect of divorce on children similarly indicates that the conflict associated with divorce, rather than the breakup of the family, is primarily responsible for many of the problems seen in children whose parents divorce (e.g., Emery, 1988; Long \& Forehand, 1987). Because at least $40 \%$ of all children born in the late $1970 \mathrm{~s}$ and early $1980 \mathrm{~s}$ are likely to experience a divorce (Glick \& Lin, 1986), and many more will live in intact families marked by a high degree of parental discord, the impact of marital discord on children warrants attention.

The relation between marital discord and child behavior problems was well documented in Emery's (1982) seminal review. However, the conclusion that marital conflict is associated with children's adjustment needs to be examined more closely for two reasons. First, relatively few of the studies investigating marital discord and divorce published at that time specifically measured interparental conflict, but focused instead on marital quality using self-report measures of global marital satisfaction or interviews of unknown reliability and validity. Although marital satisfaction and conflict are likely to be associated, unhappy marriages are not always marked by overt conflict, and most maritally satisfied couples occasionally engage in conflict. Moreover, marital satisfaction is also correlated with other factors that may affect children's adjustment (e.g., parent-child relations) (Belsky, 1981). Thus, studies using measures of marital satisfaction provide only indirect evidence that marital conflict is associated with children's adjustment. Sec-

Preparation of this article was supported by National Institute of Mental Health Grant R01 MH44078-01 and a Faculty Scholar Award from the W. T. Grant Foundation to Frank D. Fincham.

We thank Carol Diencr, Ross Parke, and Thomas Bradbury for their helpful comments on earlier drafts of the article.

Correspondence concerning this article should be addressed to John H. Grych or Frank D. Fincham, Department of Psychology, University of Illinois, 603 East Daniel Strect, Champaign, Illinois 61820. ond, little attention has been paid to the processes that might give rise to the association between marital conflict and child problems, and specific causal hypotheses rarely have been tested.

In view of these observations, it is necessary to analyze more precisely the association between marital conflict and child adjustment and to explore processes that may account for this association (cf. Waters, Jouriles, Smith, \& Richters, 1988). The purpose of the present article, therefore, is twofold. We first review studies assessing marital conflict and child adjustment to provide a more detailed description of the relation between them. Although several parameters of the association between marital conflict and child problems have been identified, little is known about the mechanisms that underlie the association. We then present a framework designed to organize existing studies and to facilitate research into the processes that may give rise to this relation.

\section{THE ASSOCIATION BETWEEN MARITAL CONFLICT AND CHILDREN'S ADJUSTMENT}

\section{Review}

In this section we examine evidence concerning the existence of a relation between marital conflict and child adjustment, consider factors that may influence the strength of this relation, and then discuss mechanisms that have been proposed to account for the association between marital conflict and child problems.

\section{The Nature of the Relation Between Marital Conflict and Child Problems}

Both marital conflict and child adjustment are multidimensional constructs. Marital conflict can vary in frequency, intensity, content, and resolution and can be overt or covert. All marriages are characterized by some degree of conflict, and it is unlikely that all expressions of marital conflict are stressful 
for children. In fact, exposure to some types of conflict may promote the development of constructive problem-solving or coping strategies. Because marital conflict can be expressed in myriad ways, it is important to identify which dimensions of marital conflict are related to child problems. Later we consider evidence pertaining to several of these dimensions (sce Dimensions of ( Conflict). Similarly, child adjustment is a global term that encompasses elements such as the adaptiveness and appropriateness of children's behavior, emotional well-being, self-concept, and achievement. Understanding the relationship between marital conflict and child adjustment thus also requires assessment of a wide range of adjustment indexes to determine if some outcomes are more closely related to exposure to conflict than others.

Approximately 20 studies have been published investigating the relation between marital conflict and children's adjustment. Although, as noted earlier, many of the studies reviewed by Emery (1982) actually measure marital satisfaction, others provide more direct evidence for the existence of an association between marital conflict and child behavior. The findings of two early studies indicate that openly expressed marital conflict is more closely associated with child problems than is marital dissatisfaction (Hetherington, Cox, \& Cox, 1982; Rutter et al., 1974; see also Emery \& O'Leary, 1984; Johnson \& O'Leary, 1987). Hetherington et al. (1982) found that only the degree of conflict to which children were exposed was related to adjustment problems in children. "Encapsulated conflict," or conflict of which children were not aware, was not associated with behavior problems. Similarly, child problems were found to be more highly associated with unhappy marriages that were quarrelsome, tense, and hostile than to unhappy marriages characterized by apathy and indifference (Rutter et al., 1974).

Since Emery's (1982) review, more than a dozen studies have been published that specifically assess the relation between marital conflict and chilren's adjustment. Most of this research examines overt conflict, or conflict of which children are likely to be aware. These studies have documented associations between marital conflict and a range of negative child outcomes, including externalizing problems such as conduct disorder (e.g., Johnson \& O'Leary, 1987; Jouriles, Murphy, \& O'Leary, 1989; Wierson, Forehand, \& McCombs, 1988), aggression (e.g., Jacobson, 1978; Johnston, Gonzalez, \& Campbell, 1987), and delinquency/antisocial behavior (Emery \& O'Leary, 1984; Peterson \& Zill, 1986) and internalizing problems such as depression (Johnston et al 1987 ; Peterson \& Zill, 1986) and anxiety/withdrawal (e.g., Long, Slater, Forehand, \& Fauber, 1988; Wierson et al., 1988). Several investigations have also reported that social competence (Emery \& O'Leary, 1984; Long, Forehand, Fauber, \& Brody, 1987), cognitive competence (Long et al., 1987; Wierson et al., 1988), and grade point average (GPA; Long et al., 1987; Wierson et al., 1988) are related to marital conflict. Several studies have also found relationships between children's perceptions of family conflict and negative child outcomes (e.g., Enos \& Handal, 1986; Farber, Felner \& Primavera, 1985; Slater \& Haber, 1984), but only studies that assess marital conflict are considered in the present article.

Table 1 presents a summary of studies that examine the relationship between marital conflict and children's adjustment. For each study, the table (a) lists characteristics of the sample, (b) identifies whether independent or nonindependent raters of marital conflict and child adjustment are used, and (c) provides a brief summary of results. To organize these studies, Table 1 is divided into two major sections: studies of marital conflict in the context of parental separation or divorce (which often include a comparison group of children from intact families) and studies of children from intact families. Studies using divorced and intact families are distinguished because children who have experienced a divorce may be exposed to unique stressors (e.g., separation from a parent) that children in intact families do not face. Additionally, the fact that the marital discord in divorced families led to dissolution of the marriage suggests that this group may differ in some way from families that remained intact. Within the studies using intact families, we have distinguished further between those examining children who had been referred for psychological treatment and those using nonclinic samples, as Emery (1982) documented a stronger relation between marital dissatisfaction and behavior problems in families with a clinic-referred child.

Many recent studies of marital conflict and children's adjustment have heeded the methodological criticisms of earlier research raised by Emery (1982). Although a few studies include measures of unknown or questionable reliability (e.g, Peterson \& Zill, 1986; Tschann, Johnston, Kline, \& Wallerstein, 1989), most use well-validated, reliable measures of children's adjustment and marital conflict. Several of the studies listed in Table 1 also have used separate raters of marital and child problems, thus avoiding the nonindependence of data and potential bias that results from using the same source for information about both constructs. These studies have most commonly used teachers as judges of child adjustment. It should be noted, however, that teacher ratings reflect a limited sample of children's behavior, and that teachers are more reliable raters of externalizing than internalizing behaviors (e.g., Zaslow, 1989). A few of the studies in Table 1 also have obtained measures of marital conflict from the children. Because different raters have different perspectives and are affected by different sources of error (see Achenbach, McConoughy \& Howell, 1987), the optimal approach to assessing the relationship between marital conflict and child behavior involves the use of multiple sources of information for each construct.

Table 1 shows that 15 of 19 studies (79\%) provide support for the existence of a relation between marital conflict and children's adjustment: Marital conflict is related to some form of child problem in 7 of the 8 studies examining children from separated or divorced families, in 2 of the 3 using clinic samples from intact families, and in 6 of the 8 studies employing nonclinic intact families. Because of the limited number of studies and the variety of dimensions on which they differ (e.g., content and reliability of measures of marital conflict, children's age, type of sample used, data-analytic strategies), we restrict our summary of Table 1 to this simple box score.

Studies using a divorced sample indicate that marital conflict present before and after divorce is related to a range of negative outcomes, and that this association is also found in intact families included as comparison groups. For example, Long et al. (1987) found significant differences between children from high-and low-conflict families (regardless of marital status) on teacher ratings of social and cognitive competence, 
conduct disorder, problem solving, and GPA, and Wierson et al. (1988) reported that young adolescents' (from both intact and divorced families) perception of interparental conflict correlated with teacher-rated conduct disorder, anxiety/withdrawal, cognitive competence, and GPA (correlations ranged from .25 to .32 ). The extensive longitudinal study conducted by Hetherington et al. (1982) provides further evidence of the relative effects that divorce and marital conflict may have on children. They reported that in the first year following divorce children from divorced families marked by high conflict functioned less well than those characterized by low conflict, who in turn exhibited more behavior problems than children from intact families. However, two years after the divorce boys from high-conflict intact families displayed more aggressiveness and acting out behavior than boys from low-conflict divorced families. Although girls who had experienced divorce did not differ from girls from intact families two years after the divorce, girls living in families marked by high conflict exhibited greater attention seeking, whining, and demandingness at home and at school than girls living in low-conflict families.

One study using a divorced sample (Shaw \& Emery, 1987) that did not clearly support the association between marital conflict and child problems found that the degree of acrimony present between parents after separation (measured as the extent of disagreement over postseparation issues such as visitation, custody, and child support) was significantly correlated with maternal reports of internalizing problems, but did not significantly predict internalizing problems when the level of maternal depression was controlled statistically.

Research on the relation between marital conflict and adjustment using intact families in which a child had been referred for psychological treatment also provides evidence that supports this association. For example, Emery and O'Leary (1982) found that boys' perception of the frequency of marital conflict was related to maternal ratings of conduct disorder, immaturity, and delinquency (correlations ranged from .35 to .41) on the Behavior Problem Checklist (Quay, 1977). Porter and O'Leary (1980) found correlations of similar magnitude to those reported by Emery and O'Leary (1982) between maternal ratings of openly expressed marital conflict and a range of adjustment problems in boys, but found that mothers' ratings of marital satisfaction were not significantly associated with child problems. This suggests that the relation between conflict and child behavior was not simply an artifact of marital distress.

In contrast, Jouriles, Barling, and O'Leary (1987) reported significant correlations between parent-child aggression and behavior problems but no relationship between marital conflict and behavior problems. This study involved children referred to a facility for women and children from maritally violent families; all of the mothers in the sample had been recent victims of marital violence, and $91 \%$ of the children had also been targets of parent-child aggression within the previous year. Being the victim of parental aggression is likely to be more stressful than witnessing marital conflict, and so exposure to parental conflict may be a much poorer predictor of behavior problems in such a sample. Further, given the level of aggression present in these families, variance in the measure of children's exposure to conflict may have been restricted (means and variances were not reported).
Studies examining nonclinic intact families also tend to support an association between interparental conflict and child problems. For example, Jouriles et al. (1989) reported that the Physical Aggression subscale of the Conflict Tactics Scale (Straus, 1979), a measure of aggression between spouses, predicted parental ratings of conduct disorder, personality disorder, inadequacy/immaturity, and clinical levels of child behavior problems after controlling for level of marital satisfaction. Similarly, Johnson and O'Leary (1987) found that parents of girls rated as high on the Conduct Disorder subscale of the Child Behavior Checklist (Achenbach \& Edelbrock, 1983) reported more interparental hostility and aggression than did parents of girls not viewed as exhibiting conduct disorders, although the two groups of parents did not differ in marital satisfaction.

Thus, recent research documents a modest but consistent relationship between interparental conflict and children's adjustment, and several studies indicate that conflict predicts child problems above and beyond indexes of marital satisfaction. However, as noted previously here, it is critical to examine the relationship between marital conflict and child adjustment more closely if the mechanisms underlying it are to be understood. Therefore, in the next two sections we discuss (a) the relation of specific dimensions of marital conflict to child adjustment and (b) demographic variables that may influence this relationship.

\section{Dimensions of Conflict}

Several dimensions of marital conflict may be important to consider. The frequency, intensity, content, and resolution of conflict in particular may affect the stressfulness of marital conflict for children and thus may be related to the existence of child problems. We consider research examining each of these factors in turn.

Frequency. Increased exposure to interparental conflict potentially could have two contrasting effects: It might lead to fewer behavior problems because children become desensitized to marital conflict, or conversely more frequent conflict may sensitize children to conflict and lead to a greater incidence of adjustment problems. Available evidence supports the latter hypothesis in that more frequent open conflict is associated with increased behavior problems (Johnston et al., 1987; Long et al., 1987, 1988; Porter \& O'Leary, 1980; Wierson et al, 1988). In a study of naturally occurring episodes of interparental anger, children exposed to more frequent marital conflict reacted more intensely when exposed to a later episode of parental conflict than did children who had experienced less frequent conflict (E. M. Cummings, Zahn-Waxler, \& RadkeYarrow, 1981). Additionally, children who had witnessed two angry confrontations between adult experimenters in a laboratory behaved more aggressively toward a playmate than those who had observed only one such conflict (E. M. Cummings, Iannotti, \& Zahn-Waxler, 1985). Although these latter studies examined only children's immediate reaction to displays of anger, they suggest that increased exposure to conflict may have increasingly negative effects.

Research on children's long-term adjustment to divorce is consistent with this conclusion because behavior problems 
Table 1

Studies Examining the Link Between Marital Conflict and Childrens Adjustment

\begin{tabular}{cccc}
\hline Study & Sample & Source & Comment \\
\hline
\end{tabular}

Hetherington, Cox, \& $\operatorname{Cox}(1982)$

72 boys and 72 girls of nursery school age, half from divorced families, half from intact families

Jacobson (1978)

Johnston, Gonzalez, \& Campbell (1987)

Long. Forehand, Fauber, \& Brody (1987)

Long, Slater, Forehand, \& Fauber (1988)

Shaw \& Emery (1987)

52 4- to 12-year-old children ( 26 boys; 26 girls) and their parents

38 3- to 13-year-old children and their mothers

4011- to 15-year-old adolescents ( 20 boys 20 girls); half from divorced families

3511 - to 15-year-old adolescents ( 31 boys, 4 girls); 23 from divorced families, 12 from intact families

40 5- to 12-year-old children of separated parents (19 boys, 21 girls)

Tschann, Johnston, Kline, \& Wallerstein (1989)

1782 - to 18-year-old children $(91$ boys, 87 girls) whose parents had separated within the previous year

Studies with divorced families

Independent ratings of marital conflict and child adjustment obtained

Single source provides ratings of marital conflict and child adjustment

Single source provides ratings of marital conflict and child adjustment

Independent ratings of marital conflict and child adjustment obtained

Independent ratings of marital conflict and child adjustment obtained

Single source provides ratings of marital conflict and child adjustment

Independent ratings of marital conflict and child adjustment obtained
In the first year after divorce, children displayed more behavior problems than children from high-conflict intact families both at home and at school; at 2 yrs after divorce, boys from high-conflict intact families were more aggressive and exhibited less prosocial behavior than boys from low conflict divorced families; girls from highconflict families displayed greater attention-seeking, whining, and demandingness than girls from low-conlict families

Ratings by the custodial parent of interparental hostility experienced before marital separation correlated with the same parent's ratings of children's aggression $(r=.29)$, inhibition $(r=.34)$, and overall severity $(r=.43)$ on the LBC; concurrent measures of interparent hostility were not correlated with ratings of child problems

Combined parental reports of verbal and physical aggression were unrelated to parental ratings of behavior problems at the time of divorce mediation; parental aggression assessed at this time did predict aggressive, withdrawn, depressed, and total score scales of CBCL 2 yrs later; parents' verbal and physical aggression 2 yrs after divorce also predicted concurrent total, withdrawn, and somatic complaint scales of CBCL.

Children from high-conflict families were rated lower by teachers on social and cognitive competence and GPA and higher on conduct disorder; independent observers judged that these children showed poorer problem solving during a parent-child conflict resolution task

Children from divorced families in which conflict continued had lower GPA, greater teacher-rated AW and CD (trend) than children from low-conflict divorced families and intact families; the low-conflict divorced group and intact group did not differ on behavior problems or parental conflict

A measure designed to assess areas of conflict between separated parents (completed by the mother) correlated with maternal ratings of externalizing problems $(r=.41)$ and with internalizing problems $(r=.24)$ on the $C B C L$; however, conflict did not predict behavior problems when maternal depression was controlled

Children's emotional adjustment (rated by clinicians) correlated with preseparation marital conflict rated by clinicians and parents $(r=-.23)$ and with postseparation parental conflict rated by parents $(r=-.28)$; maternal ratings of behavior problems correlated with preseparation marital conflict $(r=.20)$ and with postseparation parental conflict $(r=.26)$; however, path models indicated that the relation between preseparation marital conflict and indexes of adjustment were mediated by the quality of parent-child relationships; postseparation conflict was not retained in the path models

Independent ratings Children's perceptions of marital conflict correlated with of marital conflict and child adjustment obtained teacher-rated cognitive competence $(r=.28), \mathrm{CD}(r=.25)$, $\mathrm{AW}(r=.32)$, and GPA $(r=.27)$; similar correlations were found when mothers' OPS scores were used, but fathers' OPS scores were not related to the measures of adjustment; perceptions of marital conflict also predicted some outcomes two years later

Studies with intact families

Clinic-referred children

Emery \& O'Leary (1982)
508 - to 17 -year-old children

(25 boys, 25 girls)
Independent ratings of marital conflict and child adjustment obtained
Boys' perception of marital discord correlated with maternal ratings of $\mathrm{CD}(r=.39)$, Immaturity $(r=.41)$, and Delinquency $(r \cdots .35)$ scales of BPC; no correlations between girls' rating of discord and $\mathrm{BPC}$ scales 
Table 1 (continued)

\begin{tabular}{cc}
\hline Study & Sample \\
\hline $\begin{array}{c}\text { Jouriles, Barling, \& } \\
\text { O'Leary (1987) }\end{array}$ & $\begin{array}{c}455 \text { - to 13-year-old children } \\
\text { (22 boys, 23 girls) referred } \\
\text { to a center specializing } \\
\text { in treatment of women } \\
\text { and children from } \\
\text { maritally violent families } \\
\text { Porter \& O'Leary } \\
\text { (1980) }\end{array} \quad \begin{array}{c}\text { 64 5- to 16-year-old children } \\
\text { (37 boys, 27 girls) }\end{array}$
\end{tabular}

Non-clinic-referred children

E. M. Cummings, Vogel, Cummings, \& El-Sheikh (1989)

Emery \& O'Leary (1984)

Forehand, Long, Brody, \& Fauber (1986)

Johnson \& O'Leary (1987)

Jouriles, Murphy, \& O'Leary (1989)

Jouriles, Pfiffner, \& S. O'Leary (1988)

Peterson \& Zill (1986)

Rutter, B. Yule, Quinton,

Rowlands, W. Yule, \& Berger (1974)

Source

Comment

63 4- to 9-year-old children ( 34 boys, 29 girls) and their mothers

Single source provides ratings of marital conflict and child adjustment

Single source provides ratings of marital conflict and child adjustment

Single source provides ratings of marital conflict and child adjustment

132 2nd to 5th graders (71 girls, 61 boys) and their mothers

4611 - to 15-year-old children ( 20 boys, 26 girls)

42 9- to 11-year-old girls; 25 rated by parents as having conduct problems on $\mathrm{RBPC}, 17$ rated as not exhibiting conduct problems

87 5- to 12-year-old children (41 boys, 46 girls) whose parents were seeking marital therapy

6018 - to 31 -month-old children ( 30 boys, 30 giris)

1,423 12- to 16-year-old children (roughly equal no. of boys and girls)

249 children of unspecified age and gender
Independent ratings of marital conflict and child adjustment obtained

Independent ratings of marital conflict and child adjustment obtained

Independent ratings of marital conflict and child adjustment obtained

Single source provides ratings of marital conflict and child adjustment

Single source provides ratings of marital conflict and child adjustment provides ratings of marital conflict and child adjustment

Independent ratings of marital conflict and child adjustment obtained
Single source
Maternal ratings of frequency with which children witnessed physical aggression between parents was not correlated with maternal ratings on the $\mathrm{BPC}$

For boys under age 10, mother-rated OPS was correlated with maternal ratings of $\mathrm{CD}(r=.40)$ and total pathology $(r=45)$ of BPC; for boys over age 10, OPS was correlated with total pathology $(r=.43)$, socialized delinquency $(r=.42)$, personality disorder $(r=.45)$, and inadequacy/ immaturity $(r=.63)$; there were no significant correlations between OPS and behavior problems in girls

Maternal ratings of the degree of physical interparental conflict were not correlated with maternal ratings of CBCL however, children from families with greater physical interparental conflict and those rated as expressing clinical levels of behavior problems on the CBCL exhibited more distress when watching videotaped interactions involving anger between two adults

Mothers' OPS correlated with maternal ratings of total pathology scale of BPC: for girls $(r=.24)$; for boys, $(r=.20)$; no correlation between mothers' OPS and teacher-rated BPC

OPS (average of mother and father ratings) was not correlated with teacher ratings of CD on AW on RBPC

Maternal OPS scores correlated with own ratings of $C D$ $(r=.30)$ and paternal OPS scores correlated with own CD ratings $(r=.19)$; child's rating of marital conflict correlated with mothers' ratings of $\mathrm{CD}(r=.22)$, but not with fathers' CD rating

Combined parental ratings of interspousal aggression on CTS predicted parental ratings of $\mathrm{CD}$ and inadequacy/ immaturity on the BPC for boys and inadequacy/ immaturity for girls after controlling statistically for level of marital satisfaction, child's gender, and age

Maternal OPS ratings were correlated with maternal reports of conduct problems for boys $(r=.22)$ and girls $(r=.32)$

Children from families with a higher degree of marital conflict rated by one parent (usually the mother) were were rated as more depressed/withdrawn, antisocial, and hyperactive/impulsive than children whose parents reported less conflict

A significantly greater percentage of children with teacher or parent reported "psychiatric disorder" lived in homes marked by severe marital discord (defined by hostility, tension, quarrelsomeness) than children not exhibiting behavior problems; marital discord ratings were obtained during semistructured interviews with one or both parents

Note $\mathrm{LBC}=\mathrm{Louisville}$ Behavior Checklist $\mathrm{CBCL}=\mathrm{Child}$ Behavior Checklist $\mathrm{CD}=$ Conduct Disorders subscale of $\mathrm{CBCL} ; \mathrm{AW}=$ anxiety/withdrawal; OPS = O'Leary-Porter Scale (openly expressed conflict); BPC = Behavior Problem Checklist; RBPC = Revised Behavior Problem Checklist; GPA = grade point average; CTS = Conflict Tactics Scale. 
have been found to decrease when conflict decreases after a divorce (Hetherington et al., 1982; Long et al., 1987, 1988; Wallerstein \& Kelly, 1980). For example, Long et al. (1988) found that adolescents from recently divorced families in which conflict continued at a high level after the divorce exhibited greater anxiety/withdrawal problems and conduct disorders than did youths from divorced families in which conflict had substantially decreased. Moreover, the adolescents who experienced a decrease in conflict did not differ from adolescents from intact families in the degree of behavior problems they exhibited.

Intensity. Marital conflicts differ widely in their intensity, ranging from calm discussion to physical violence. It may be that exposure to low-intensity conflict, even if it is frequent, is unrelated to child problems and that marital conflict is upsetting to children only when it involves hostility or physical aggression. Intensity of conflict has been examined in a number of studies. Johnston et al. (1987) reported that the degree of verbal and physical aggression between divorcing parents was related to parental reports of behavior problems assessed two years after the divorce, and measures of interparental aggression two years after divorce were related to the Somatic Complaint, Withdrawn/Uncommunicative, and Total Pathology scales of the Child Behavior Checklist (Achenbach \& Edelbrock, 1983). Studies of marital violence have also reported correlations between these intense types of conflict and child behavior problems (e.g., Jouriles et al., 1989; Wolfe, Jaffe, Wilson, \& Zak, 1985).

In a series of studies examining children's immediate response to anger between others, E. M. Cummings and his colleagues have found that children exhibit more distress when observing naturally occurring anger between their parents that involves physical aggression (E. M. Cummings et al., 1981), and children watching videotapes of angry exchanges between adults that included physical aggression expressed more distress than when watching tapes that exhibited only verbal anger (E. M. Cummings, Vogel, Cummings, \& El-Sheikh, 1989). Children who report a history of physical conflict between their parents also exhibit greater distress (E. M. Cummings et al., 1989) and increased efforts to comfort their mother when she is angrily confronted during an experimental session (J. S. Cummings, Pellegrini, Notarious, \& Cummings, 1989) than children not reporting such conflicts. However, E. M. Cummings et al. (1989) did not find a direct association between history of physical interparental conflict and clinical levels of behavior problems.

This evidence indicates that conflict involving physical aggression is more upsetting to children and may be more closely linked to behavior problems than less intense forms of conflict. However, assessing the degree of physical aggression present during conflict is only one possible operationalization of intensity. Intensity of marital conflict can also be conceptualized as the degree of negative affect or hostility expressed by parents. Because both verbal and nonverbal forms of anger have been shown to cause distress in children (E. M. Cummings et al, 1989), it is important to consider other aspects of intensity to gain a more complete understanding of the relation between conflict intensity and child problems.

Content. The content of interparental conflict may also affect children's responses. However, none of the studies listed in
Table 1 directly assessed this dimension. Other research provides some evidence concerning the role of content in children's response to conflict. Dunn and Munn (1985) studied conflict in the families of 2-year-olds and found that the children responded differently to mother-sibling conflict depending on the topic of the conflict. Conflicts pertaining to the siblings' aggressive behavior led to negative affect in children, whereas conflicts over family rules were more likely to be met with laughter. These results were not simply due to the emotion expressed by the participants in the conflict; children also responded differently to various topics that were emotionally neutral. Although this study examines mother-sibling conflicts, it suggests that children as young as 2 years of age are sensitive to the content of conflicts.

One might speculate that conflict concerning the child may be more distressing to the child and thus may be more closely related to behavior problems. Two studies support this idea. Block, Block, and Morrison (1981) found that parental disagreement on child-rearing values predicted adjustment problems in children one to four years later, and Snyder, Klein, Gdowski, Faulstich, and LaCombe (1988) reported that a measure of conflict over child rearing was related to a range of behavior problems in children. Although these studies suggest that child-related conflict is related to children's adjustment, neither study assessed children's exposure to parental conflict or compared this type of conflict with other topics of conflict. More important, parental disagreement about child rearing may be associated with behavior problems in children because it leads to inconsistent discipline, which is also related to child problems (see Mechanisms).

Resolution. How conflicts are resolved may moderate their impact on children. Parents who successfully resolve their conflicts provide positive models of problem solving for their children, which may lead to increased social competence and coping skills, whereas poor conflict resolution may produce continued tension in the family and lead to more frequent episodes of conflict. Very little research has examined the effect of conflict resolution on children's response to marital conflict, and none of the studies in Table 1 assessed this dimension. However, a recent study supports the influence of conflict resolution on children's immediate response to conflict between others. E. M. Cummings et al. (1989) found that 6- to 9-year-old children, but not 4- and 5-year-olds, reported less negative affect when angry interactions between adults resulted in clear resolution of the conflict than when the conflict was left unresolved. This study suggests that investigation of the role of resolution is a promising avenue for future research.

\section{Demographic Variables}

In addition to investigating specific dimensions of marital conflict, a number of demographic variables that may influence the strength of the association between conflict and adjustment have been examined. The variables considered most often are children's gender, whether they have been referred for treatment, and their age. We consider each of these factors in turn.

Gender. Early studies examining marital conflict and child adjustment found that conflict was more closely linked to be- 
havior problems in boys than in girls (Emery \& O'Leary, 1982; Hetherington et al., 1982; Porter \& O'Leary, 1980), a finding consistent with studies of children's adjustment to divorce and other psychosocial stressors (Emery, 1988; Zaslow, 1989; Zaslow \& Hayes, 1986). One explanation offered for this difference is that girls are more likely to be shielded from conflict than boys. However, it appears that boys and girls are equally likely to be exposed to and are equally aware of marital conflict (Emery \& O'Leary, 1982; Porter \& O'Leary, 1980). Consistent with this finding, more recent investigations have reported significant associations between marital conflict and girls' adjustment, suggesting that both boys and girls are adversely affected by exposure to interparental conflict (Emery \& O'Leary, 1984; Johnson \& O'Leary, 1987; Jouriles, Pffffner, \& O'Leary, 1988; Long et al., 1987; Peterson \& Zill, 1986).

Other studies using measures of marital satisfaction rather than marital conflict have found that marital distress is most closely related to externalizing problems in boys and internalizing problems in girls (Block et al., 1981; Hess \& Camara, 1979; Whitehead, 1979). When marital conflict is assessed, however, these gender differences are not obtained. Several studies have reported significant relations between interparental conflict and internalizing and externalizing problems in both boys and girls (e.g., Johnson \& O'Leary, 1987; Long et al., 1988). Thus, gender differences found in research investigating marital dissatisfaction and divorce do not appear to extend to studies specifically examining marital conflict and children's adjustment. It is likely, then, that gender differences in the form or incidence of behavior problems are due to some factor associated with marital distress or divorce other than interparental conflict. ${ }^{1}$

Although there is evidence for sex differences in children's response to psychosocial stress (Zaslow \& Hayes, 1986), studies examining boys' and girls' responses to background anger have produced inconsistent results. No sex differences were obtained in three of the studies conducted by Cummings and his colleagues (E. M. Cummings et al., 1981; E. M. Cummings, Zahn-Wexler, \& Radke-Yarrow, 1984; J. S. Cummings, et al., 1989), but in two others they found that boys were more likely to respond to adult anger with aggression and anger than were girls, and girls tended to exhibit greater distress than boys (E. M. Cummings et al., 1985, 1989). Consistent with these latter studies, Feshbach (1970) argued that boys tend to respond to a stressor with aggression, whereas girls are more likely to inhibit their behavior (see also Block et al., 1981).

Clinic versus nonclinic samples. Stronger patterns of associations between marital conflict and child behavior problems tend to be found in families of clinic-referred children than in community volunteers. For example, Porter and O'Leary (1980) and Emery and O'Leary (1982) reported several correlations greater than .40 between marital conflict and subscales of the Behavior Problem Checklist (Quay, 1977) in samples of clinicreferred children, whereas correlations between similar measures reported in studies using community samples rarely exceeded .35 (e.g., Emery \& O'Leary, 1984; Wierson et al., 1988).

The magnitude of associations found in the two populations may be due to a number of factors, including the existence of more severe behavior problems in clinical samples and a greater range of scores on measures of adjustment in children referred for treatment. Decreased variance in measures of behavior problems in nonclinical groups may attenuate the magnitude of correlations obtained with this population. ${ }^{2}$ Stronger associations between measures of conflict and adjustment in clinical samples might also be due to a tendency for clinic parents to perceive their children as more disturbed. Several studies have shown that perceptions of child maladjustment are influenced by parental characteristics (e.g., Brody \& Forehand, 1986; Griest, Wells, \& Forehand, 1979; Webster-Stratton, 1988), and when a parent provides information on both marital conflict and child problems it raises the possibility that some third factor, such as marital dissatisfaction or depression, may inflate the correlation between marital conflict and child behavior. A recent study examining this issue found that children's self-reports of behavior problems and parents' psychological symptoms each accounted for significant unique variance in parental reports of child problems (Phares, Compas, \& Howell, 1989). Thus, it is likely that the reports of parents who refer their children for treatment are a function of both the child's actual behavior and the parent's own characteristics.

Whether clinic or nonclinic samples are used also has implications for whether sex differences are found in the association between interparental conflict and behavior problems. Studies that have found no relationship between conflict and behavior problems in girls have used clinic samples (Emery \& O'Leary, 1982; Porter \& O'Leary, 1980), whereas studies using community volunteers generally did not uncover sex differences (e.g., Emery \& O'Leary, 1984, Wierson et al, 1988). Although this difference could be due to a larger number of boys than girls in clinic samples or to a higher incidence of externalizing than internalizing problems in clinic samples, both Emery and O'Leary (1982) and Porter and O'Leary (1980) studied roughly equal numbers of boys and girls who did not differ significantly in maternal reports of internalizing or externalizing problems.

Age of the child. Interestingly, one parameter that has not been consistently related to behavior problems is the age of the child. There has been little systematic research on age differences, but existing data suggest that no one age group is particularly vulnerable to the effects of marital conflict. Porter and O'Leary (1980) found that specific behavior problems were associated differentially with marital conflict at different ages for the boys in their sample, but did not test the differences between the correlations for statistical significance. Hetherington $(1979,1984)$ suggested that children of different ages differ in their awareness of and ability to cope with interparental conflict, but that no one particular age group is likely to be more affected than another. Although young children may be less able to cope with conflict, they are less likely to be aware of conflict and its implications, whereas older children have a larger repertoire of coping responses but are likely to be more aware of the causes and consequences of conflict (Hethering-

\footnotetext{
'Recent research indicates that a number of factors influence boys' and girls' adjustment to divorce. Most important, the form of the postdivorce family, especially which parent has custody and whether and when the custodial parent remarries, appears to be critical in understanding gender differences (see Zaslow, 1988, 1989).

${ }^{2}$ We are grateful to an anonymous reviewer for suggesting this possibility.
} 
ton, 1984; Hetherington, Stanley-Hagen, \& Anderson, 1989). This idea has been supported by work on children's response to anger between adults, which shows that 4- to 5-year-old children evidence more distress, but also more adaptive coping responses, than 2- to 3-year-olds (E. M. Cummings, 1987).

\section{Summary and Critique}

Marital conflict appears to be more highly related to child problems than measures of marital satisfaction. Research on the association between marital conflict and child behavior problems indicates that (a) exposure to more frequent episodes of interparental conflict leads to greater distress in children and a greater incidence of behavior problems, and conversely the cessation of conflict is associated with a reduction of problem behaviors; (b) exposure to more intense forms of marital conflict, such as conflict involving physical aggression, is also related to child problems and is more upsetting to children than less intense conflict; (c) children as young as 2 years may be sensitive to the content of conflict; (d) interparental conflict is associated with adjustment problems in both boys and girls; (c) correlations between conflict and behavior problems appear to be higher in clinic samples than nonclinic samples; (f) age is related to immediate responses to conflict but appears to be unrelated to the incidence or severity of behavior problems.

Although these studies have begun to document the association between marital conflict and children's adjustment, most research has focused on the frequency and to a lesser extent the intensity of marital conflict, leaving largely unexplored the influence of other dimensions of conflict (e.g., resolution, content). Thus, the relative importance of the various dimensions of conflict is unknown. Similarly, assessment of child adjustment has emphasized measures of behavior problems and rarely has included other indexes of adjustment. Finding that conflict is related to behavior problems clearly is important, but it is also possible that exposure to marital conflict may have less noticeable effects that nevertheless are problematic for the child, such as low self-esteem and poor peer relations. Studies showing that conflict is related to social (e.g., Long et al., 1987) and cognitive (e.g., Wierson et al, 1988) competence indicate that exposure to conflict may affect children's functioning more broadly and suggest that additional exploration of these domains may be fruitful.

Despite these limitations, assessment of interparental conflict rather than marital satisfaction provides a more precise picture of the association between marital and child problems than research available at the time of Emery's (1982) review. Moreover, the findings from this literature provide a starting point for investigating familial processes that may give rise to child behavior problems. We next discuss the mechanisms proposed to account for this relation and examine research relevant to them.

\section{Mechanisms Accounting for the Association Between Marital Conflict and Child Problems}

Most of the hypotheses advanced to explain the relationship between marital conflict and children's adjustment have presumed that marital conflict affects children. This is a reason- able viewpoint because even though children's behavior is also likely to influence marital interaction (Bell, 1979), there is reason to believe that this association does not simply reflect child effects. For example, O'Leary and Emery (1984) reported that the probability of having a problem child given the existence of marital distress is greater than the probability of experiencing marital distress given the presence of a problem child, and improvement of a child's problem behavior does not seem to result in the alleviation of marital problems (Oltmanns, Broderick, \& O'Leary, 1977). It is likely that the relation between marital and child problems is reciprocal, but given the goal of understanding the development of adjustment problems in children, and consistent with current theorizing, we focus on how marital conflict may affect children. Hypotheses offered to account for the association between marital conflict and child behavior problems can be divided into those positing direct effects of conflict on children's adjustment and those arguing that the impact of marital conflict is indirect and is mediated by parent-child relationships. The most frequently discussed direct mechanisms are modeling and stress, whereas hypotheses proposing indirect effects focus on changes in the character of parent-child interaction and discipline practices. We consider each of these hypotheses in turn.

\section{Modeling}

Modeling is perhaps the most appealing mechanism presumed to underlie the marital conflict-child behavior association because it is well documented that children tend to imitate their parents (Bandura, 1973, 1977). Because of their salience, affective relationship, and importance to their children, parents can be powerful models, particularly for the same-sex child. Children learn a great deal about interpersonal relationships from watching their parents (Belsky, 1981), and it may be that engaging in aggressive or hostile behaviors during conflicts provides children with maladaptive models of problem solving or conflict resolution.

One study that has attempted to relate parents' conflict behaviors to children's behavior problems provides some support for the modeling hypothesis. Johnson and O'Leary (1987) found that the mothers of girls with conduct disorders were more hostile and the fathers more aggressive than the mothers and fathers of girls without conduct disorders. The two groups of parents did not differ in marital satisfaction, suggesting that the behaviors exhibited by parents during conflict have greater impact than marital distress. Although Johnson and O'Leary's study does not include boys, it nevertheless indicates similarities in the behavior of parents and their children.

It is important to note that modeling does not simply consist of the mimicry of behavior (Bandura, 1989). Two further aspects of modeling are briefly noted. First, modeling involves the acquisition of information about behavior. If parents are hostile and aggressive during conflicts, children may learn that aggression is an acceptable way to deal with disagreements. However, this belief is likely to be expressed in age-appropriate ways. Children who learn to be aggressive in conflictual situations might not aggress against their larger and more powerful parents, but may instead act aggressively when interacting with peers or younger children. E. M. Cummings et al's (1985) study 
of children's aggression following exposure to angry interactions between adults supports this view. After witnessing the experimenters engage in an angry verbal exchange, children exhibited increased physical and age-appropriate aggression toward a playmate.

Second, modeling may also have a disinhibitory effect on children's behavior. Exposing children to aggressive models may give children permission to be aggressive. The E. M. Cummings et al. (1985) study can be interpreted as indicating that children ceased to inhibit their aggressive impulses: Children who were rated high on aggression before exposure to anger exhibited more intense and longer lasting episodes of conflict than children considered moderate or low in aggressiveness. This suggests that witnessing angry interactions may result in children perceiving aggression as acceptable, and that children who have a tendency to be aggressive may be particularly likely to become disruptive.

The modeling hypothesis thus can account for some of the findings discussed earlier. Children need to observe their parents in conflict for modeling to occur, and hence measures of openly expressed conflict should be more closely related to behavior problems than measures of marital dissatisfaction or encapsulated conflict. Similarly, more frequent exposure to conflict should lead to greater behavior problems as children have more opportunities to observe their parents' behavior. Modeling is a promising mechanism for understanding the relationship between marital conflict and child behavior, but modeling explanations tend to be offered post hoc and need to be tested directly before conclusions can be drawn regarding their validity.

\section{Marital Conflict as a Stressor}

Marital conflict may also affect children by exposing them to a potentially intense stressor. Research on children's reactions to angry interactions between adults (background anger) indicates that exposure to parental conflict is stressful for most children; even children as young as 1 and 2 years exhibit distress when observing hostile parental interaction (Crockenberg, 1985; E. M. Cummings et al., 1981; Dunn \& Munn, 1985).

Although marital conflict appears to be stressful for children, few researchers have investigated the stress and coping processes that may explain the marital conflict-child behavior link. An exception is a series of studies examining children's observation of background anger conducted by Cummings and his colleagues (for a review, see E. M. Cummings \& Cummings, 1988). Because marital conflict is often characterized by anger, this work is relevant for understanding the relation between marital conflict and children's adjustment. In addition to demonstrating that children exhibit more distress when angry interchanges are more frequent (e.g., E. M. Cummings et al., 1985), involve physical aggression (E. M. Cummings et al, 1989), and are unresolved (E. M. Cummings et al., 1989), E. M. Cummings et al. (1984) reported individual differences in children's responses to conflict that show some consistency over time, and suggest that children may be characterized by general coping styles that differ in their utility for dealing with parental anger. However, compared with the literature on adult coping, little is known about children's coping mechanisms, particularly how they appraise stressful situations (Compas, 1987).

Experiencing intense stress can lead individuals to rely on dominant, well-learned coping responses that may be less mature or adaptive (Spielberger, 1979). Among children, this may result in reliance on behaviors such as aggression or withdrawal. Children who have tended to use these coping responses when they were younger might be expected to turn to them when threatened. E. M. Cummings et al. (1985) found that children who were judged as high on aggressiveness reacted most aggressively (more intensely and for a longer period of time) to anger between two adults. In comparison, children who were rated as low on aggressiveness were more likely to exhibit distress. Moreover, children's responses to background anger at age 1 to $2^{1 / 2}$ years were related to their reaction 5 years later, indicating that children exhibit some consistency in their response to stressors (E. M. Cummings et al., 1984).

Examining children's response to marital conflict from a stress and coping perspective is useful for exploring the processes that may occur during exposure to conflict. E. M. Cummings and his colleagues' research on how children cope with threatening situations has shed light on their immediate response to conflict, but has examined the relationship between these responses and children's adjustment in only a single study. E. M. Cummings et al. (1989) found that children rated by their mothers as displaying clinical levels of behavior problems reported more distress in response to anger between others than did children with subclinical scores, providing preliminary support for a link between immediate responses to conflict and more general adjustment problems.

\section{Parent-Child Relationships}

Interparental conflict may also be related to behavioral problems because it leads to a deterioration in parent-child relationships (Hess \& Camera, 1979; Jouriles et al., 1987; O'Leary \& Emery, 1984; Peterson \& Zill, 1988). Parent-child relationships may be affected in a number of ways. For example, parents might become withdrawn or hostile toward their children or might attempt to ally the child with them in a coalition against the other parent, thus creating loyalty conflicts for the child (Emery, Joyce, \& Fincham, 1987; Margolin, 1981).

In support of the mediating role of parent-child relationships, Tschann et al. (1989) reported that predivorce marital conflict was related to postseparation behavior problems and emotional adjustment only indirectly through its association with the quality of parent-child relationships. In contrast, Peterson and Zill (1986) found that children living in intact families marked by moderate or high levels of conflict exhibited higher levels of behavior problems than children in low-conflict families after adjusting for parent-child relationships. Although Peterson and Zill (1986) reported that higher quality parent-child relationships were related to lower levels of marital conflict, they concluded that conflict is a significant predictor of behavior problems independent of parent-child relationships. It is difficult to resolve the discrepancy in the findings from these two studies because the studies differed on a number of important dimensions, including the type of sample, instruments used to measure the constructs, who rated conflict 
and parent-child relationships, and data-analytic strategies. More research clearly is needed before conclusions can be drawn regarding the role of parent-child relationships in mediating the association between marital conflict and children's adjustment.

Several studies investigating the relation between marital discord, parent-child relations, and children's adjustment have assessed marital satisfaction rather than marital conflict. For example, Hess and Camara (1979) assessed marital harmony and parent-child relationships through interviews with divorced and nondivorced families, and found that parent-child relationships accounted for more variance in child behavior problems than did marital harmony. However, the criteria Hess and Camara (1979) used to evaluate marital harmony are unclear, and so it is difficult to determine the extent to which this variable assessed parental conflict versus marital satisfaction. Studies assessing marital satisfaction provide only indirect tests of the relationship between conflict, parent-child relationships, and child behavior. However, decreased marital satisfaction is associated with both increased conflict and poorer parent-child relations (Brody, Pillegrini, \& Siegal, 1986; Goldberg \& Easterbrooks, 1984; Johnson \& Lobitz, 1974) and thus these studies highlight the importance of the parent-child relationship for understanding the association between marital conflict and child behavior. For example, frequently occurring marital conflict may lead to greater deterioration in parentchild relationships as children become more aware of and possibly more involved in parental conflict. Children may feel they need to choose sides in the conflict or a parent may come to resent a child if he or she is perceived as a cause of conflict (O'Leary \& Emery, 1984).

Marital conflict and parent-child relations also may be linked because the hostility and aggression expressed during marital conflict may be reproduced in the parent-child relationship. Interspousal aggression has been found to be related to parent-child aggression (e.g., Jouriles et al., 1987), and parent-child aggression is related to many of the same problems as marital conflict: conduct problems, anxiety/withdrawal, and motor excess in boys and anxiety/withdrawal in girls (e.g., Jouriles et al., 1987, 1989; Wolfe et al., 1985).

Finally, it has been proposed that the impact of marital conflict may be mediated by changes in a particular aspect of parent-child relations, discipline practices (Emery, 1982). Marital conflict has been associated with within- and between-parent inconsistency in disciplining daughters (Stoneman, Brody, \& Burke, 1989), and inconsistent discipline has been linked to conduct problems and aggression as well as to juvenile delinquency (Pattcrson, 1977, 1986; Patterson \& Stouthamer-Loeber, 1984). In a longitudinal study, Block et al. (1981) found that parental disagreement about discipline was related to both subsequent divorce and later externalizing problems in boys and internalizing problems in girls. Discipline may also play a role by being the source of some parental conflicts. Since such conflicts concern the child directly, he or she is particularly likely to be exposed to them.

Although changes in discipline practices can affect children's behavior, marital conflict does not invariably lead to inconsis- tent discipline. To determine if changes in discipline account for the association between child behavior problems and marital conflict, it is necessary to show that conflict first leads to inconsistent discipline, which then causes behavior problems. If marital conflict and changes in discipline simply co-occur, it may be that conflict leads to behavior problems, which then cause parents to change or become less effective in their discipline practices. Additionally, the hypothesis that changes in discipline underlie the marital conflict-child behavior association does not explain why exposure to parental conflict is more closely related to child behavior problems than is encapsulated conflict. It may be that as conflict becomes increasingly intense and more frequent, children are more likely to be exposed to it and discipline practices are also more likely to be affected, but this possibility has not been investigated.

\section{Summary and Critique}

Several mechanisms that may account for the association between marital conflict and child behavior problems have been identified. It is plausible that marital conflict influences child behavior both directly via modeling and exposure to stress, particularly as children get older and become more aware of the nature of their parents' relationship (Belsky, 1981; E. M. Cummings \& Cummings, 1988) and indirectly through changes in parent-child relationships. However, support for mechanisms proposed to link marital conflict and children's adjustment is largely indirect. Hypotheses concerning the role of modeling in particular have not been the subject of empirical investigation. E. M. Cummings and his colleagues have made important advances in understanding how children cope with anger between adults, but only a few of their studies have involved children's exposure to parental conflict, and findings obtained with nonfamily members may not be directly applicable to children's experiences in the family. Additionally, with the exception of one study they have not attempted to link marital conflict to children's adjustment. Finally, there have been attempts to assess the relative effects of marital conflict and parent-child relationships on children's adjustment (e.g., Peterson \& Zill, 1986; Tschann et al., 1989), but these studies have produced inconsistent results.

In summary, progress has been made since Emery's (1982) review in documenting the relationship between marital conflict and child behavior problems and, to a lesser extent, in exploring mechanisms that may account for this association. However, the conclusions that can be drawn about the conditions under which marital conflict leads to adjustment problems are still quite limited. In part, our limited understanding of this association is due to a relatively narrow focus on the factors that may potentially affect it. Moreover, few studies have examined the processes that occur when children observe interparental conflict. Therefore, in the next section we examine two classes of variables - the context of conflict and children's cognitions-that have received little attention in the literature but which are likely to be particularly important for understanding how marital conflict affects children. 


\section{Toward a More Complete Understanding of the Relationship Between Marital Conflict and Children's Adjustment}

To understand the mechanisms linking marital conflict and child behavior it is important to examine processes that occur during exposure to marital conflict that may mediate this relationship. We believe that such a focus may reveal factors that influence the stressfulness of conflict for children and affect their ability to cope effectively with it. In reviewing research on how children respond to anger between others, E. M. Cummings and Cummings (1988) similarly stressed the importance of developing detailed, microanalytic models that specify the processes by which stressful events affect children. Research on stress and coping suggests that two factors are likely to be particularly important for understanding how children respond to marital conflict: the context in which conflict occurs and children's interpretation of conflict. Further, each of these classes of variables is likely to be affected by children's level of development.

The impact of a particular episode of marital conflict depends in part on the broader context in which it occurs. Factors such as the child's previous experience with marital conflict may serve to alter the stressfulness of the conflict and thus moderate the relation between conflict and adjustment problems. Contextual factors are potentially important because they provide a backdrop against which episodes of conflict are perceived, and are therefore likely to affect the child's understanding of and response to conflict.

How children interpret interparental conflict is also likely to influence children's responses (E. M. Cummings \& Cummings, 1988; Hetherington, 1984). As several writers have emphasized, the effect of a potentially stressful event is best understood by considering the child's interpretation of the event (Compas, 1987; Kagan, 1983; Rutter, 1983), and children's cognitions have been demonstrated to influence their affect and behavior in a number of contexts, for example, achievement situations (Dweck \& Leggett, 1988) and coping with illness (Tennen, Affleck, Allen, McGrade, \& Ratzan, 1984). In the family, for example, Herzberger and Tennen (1986) argued that maltreated children's interpretation of their parents' abusive acts affects their behavior, emotional development, and later interaction with the parent. Despite the potential significance of cognitive variables, few studies have assessed children's perceptions of interparental conflict (for exceptions, see Emery \& O'Leary, 1982; Johnson \& O'Leary, 1987; Wierson et al., 1988), and none have investigated how children's understanding of the causes and consequences of conflict may affect their responses.

Both the context of conflict and children's interpretation of conflict are likely to change developmentally. As children mature, they become better able to understand and cope with stressful events and more adept at regulating their emotions and behavior. Parents also treat children differently as they get older, and it is possible that the degree of conflict to which children are exposed and parents' responses to their children's attempts at intervention change with age. Although no age group appears to be particularly vulnerable to the effects of interparental discord, children's affective and behavioral re- sponses to conflict do change with age (E. M. Cummings et al., 1984, 1985); therefore, a comprehensive model of the relation between marital conflict and children's behavior needs to consider the variety of ways that children's development may affect this relationship.

\section{A FRAMEWORK FOR INVESTIGATING CHILDREN'S RESPONSE TO MARITAL CONFLICT}

\section{Overview}

The studies reviewed earlier document a reliable association between marital conflict and child problems, but there is little data examining why this association exists. To understand more fully the relation between interparental conflict and child adjustment, explanatory models need to be developed. Toward that end, we present a framework that organizes existing research and identifies new directions for exploring the processes that give rise to this association. We present an overview of the framework, describe its components, provide an illustration of how a child processes conflict behavior, and discuss the implications and future research directions suggested by the framework.

The framework we offer draws on models proposed by $\mathrm{E}$. M. Cummings and Cummings (1988) and by Bradbury and Fincham $(1987,1989)$. E. M. Cummings and Cummings (1988) described a number of influences on how children cope with anger between adults, including the stimulus characteristics of the anger episode and characteristics of the child. Because most marital conflicts are characterized by some degree of anger or hostility, the Cummings and Cummings model can provide insight into factors that influence how children cope with this type of stressor. However, even though Cummings and Cummings noted the importance of cognitive appraisal, the role of cognition is largely undeveloped in their model. Our elaboration of cognitive processing draws on Bradbury and Fincham's $(1987,1989)$ attempt to articulate the role of covert factors in behavior exchanges between intimates. Although designed to examine adult interaction, the broad distinctions drawn in that model are likely to prove useful for understanding children's response to interparental conflict.

Our framework tries to address the limitations of existing research identified earlier and focuses on the child's attempt to understand and respond to an episode of marital conflict. The framework outlines processes that may moderate the stressfulness of conflict for the child (see Figure 1) and highlights the importance of the context of parental conflict, children's cognitions, and their level of development. Our emphasis on cognition should not be construed as a diminuation of the role of affective processes in children's response to conflict. Instead our focus on the role of cognitive factors in mediating the relationship between marital conflict and maladjustment is due in part to the relative neglect of children's cognition in this area of research. However, it must be recognized that cognition and emotion are intimately connected (e.g., Campos, Campos, \& Barrett, 1989); in fact, Sroufe (1979) even argued that they are 


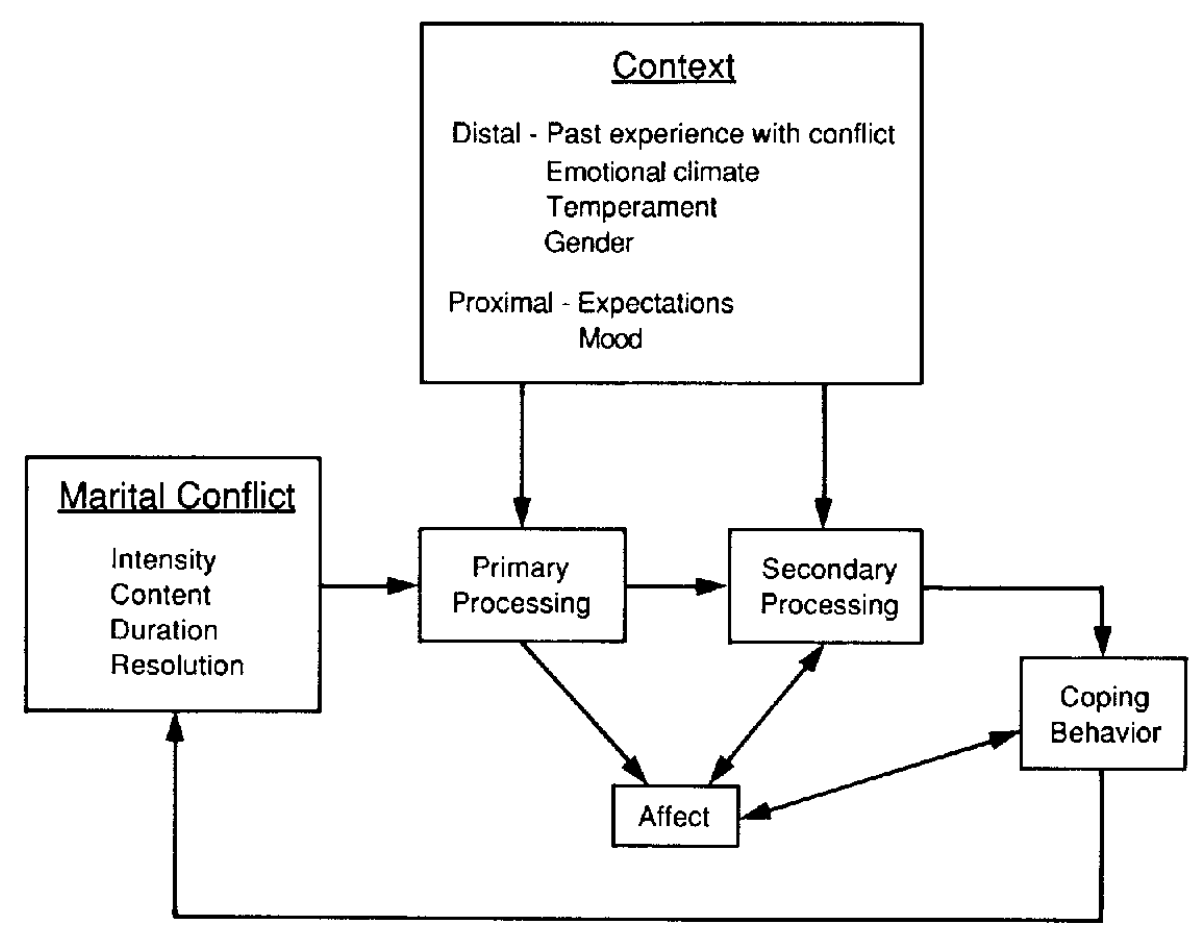

Figure 1. A cognitive-contextual framework for understanding children's responses to marital conflict.

"two aspects of the same process" (p. 491). Coping with marital conflict may be understood as a task involving the regulation of emotional arousal and enactment of effective behavioral strategies in which cognition plays a central role. In the framework we attempt to identify factors that affect this process and to outline some of the ways that cognition and emotion may interact.

Interparental conflict is conceptualized as a stressor that leads to an attempt by the child to understand and cope with the conflict. Consistent with recent conceptualizations of emotional regulation (Bretherton, Fritz, Zahn-Waxler, \& Ridgeway, 1986; Campos et al., 1989), we propose that both cognition and affect serve appraisal functions and guide the child's coping behavior. Through primary processing the child first becomes aware that a stressful event is occurring and experiences an initial affective reaction. Characteristics of the conflict episode and contextual factors are proposed to influence this initial stage of appraisal. Primary processing may then lead to secondary processing, a more elaborated stage of processing, during which the child attempts to understand why the conflict is occurring and what he or she should do in response. Secondary processing involves making an attribution for the cause of the event, ascribing responsibility and blame if relevant, and generating expectations for the efficacy of potential coping responses. In addition to being affected by characteristics of the conflict episode and contextual factors, secondary processing is influenced by the child's initial level of emotional arousal, and in turn serves to modulate affect aroused by the conflict. Both affect and secondary processing then guide the child's attempt to cope with the conflict. Successful coping leads to a reduction of negative affect, whereas unsuccessful coping may maintain or increase the child's distress.
This framework necessarily presents a simplified account of children's understanding of and response to interparental conflict. Although we focus on the child's initial response to conflict, changes in parental behavior or the child's understanding of the conflict may result in the process being repeated ${ }^{3}$ For example, attributions for the cause of conflict may change as new information is acquired, and a child may engage in coping strategies that alter the course of the conflict. Moreover, the child may become directly involved in the conflict, effectively turning marital conflict into family conflict. Thus, a complete model of family conflict would account for the interaction of the cognitive, affective, and behavioral responses of all of the participants over the course of the episode, but such a model is beyond the scope of this article. We hope the framework will serve as a heuristic device for delineating some of the processes that occur when a child observes marital conflict, and is in principle applicable to other family members as well.

\section{Components of the Framework Properties of Conflict Episodes}

As seen in our earlier review, several characteristics of conflict have been associated with children's response to conflict. The features of a conflict episode that are proposed to have the greatest impact on children are its intensity, content, duration, and resolution.

\footnotetext{
${ }^{3}$ The appraisal process need not only occur during the conflict episade. Children may continue to try to understand the causes and implications of marital conflict after the conflict episode has ended.
} 
Conflicts of greater intensity are likely to cause greater distress in children. The intensity of conflict may be determined by a number of factors, including the degree of negative affect or hostility expressed and the occurrence of physical aggression. The content of conflicts can vary widely but certain conflicts, such as those concerning the child or the state of the marriage, may be more upsetting to children than other less threatening topics. Conflicts involving children may be particularly stressful because they may lead children to question their place in the family, their parents' feelings about them or to blame themselves for family turmoil. Although the duration of conflict episodes has not received attention in the literature, longer lasting episodes may lead to greater distress for children because they increase the length of time children are exposed to a stressor. It should not be assumed, however, that the stress experienced by children increases linearly with exposure to conflict, because children may habituate to the conflict with time. Alternatively, children may be overwhelmed by lengthy conflict episodes, particularly if they are intense. Finally, conflicts that lack satisfactory resolution may upset children more than conflicts that are successfully resolved. As noted earlier, parents who consistently resolve conflicts in a constructive fashion provide models of effective problem solving and conflict resolution for their children, which may facilitate their child's interaction with others. Whether such benefits occur may depend largely on the other features of conflict discussed previously here. For example, frequent violent conflicts may have a deleterious effect on children even if they are successfully resolved.

Children's level of development may exert an indirect effect on their perception of conflict by influencing parents' conflict behavior. For example, parents' beliefs about development may lead them to treat children differently as they get older. Some parents may argue less frequently or less intensely in front of younger children because they perceive them as more vulnerable than older children. Parents' understanding of cognitive development is also likely to affect the explanations they give their children about the cause and meaning of marital conflict, which may in turn shape children's processing of conflict. Parents may believe, for instance, that young children cannot understand marital conflict and so do not discuss it with them. Although parents' awareness of their children's developing capacities may affect their conflict behavior, children's development is likely to have greater and more direct effects on other components of the model.

The relative importance of the dimensions of marital conflict is not known, but it may be that their effect is cumulative: Children who witness intense, drawn-out, and poorly resolved conflicts are likely to experience more stress than children who observe less-intense, short-lived conflicts that are resolved satisfactorily. However, the characteristics of conflict episodes are not the only factors that influence children's response to conflict. We turn now to consider contextual factors that are likely to affect how children interpret and cope with interparental conflict.

\section{The Context of Conflict}

Although context may encompass a broad range of factors, including the physical setting of the conflict, we propose that the psychological aspects of context (e.g., children's memory of past conflicts) may be the most important influences on children's response to marital conflict. Therefore, as in Bradbury and Fincham's (1987) model, contextual factors are considered to be "properties of the participants in an interaction, rather than ... objective aspects of the interaction itself" (p. 77). As shown in Figure 1, a distinction is drawn between distal and proximal context. Distal context refers to relatively stable or slowly changing factors and includes such elements as children's memory of previous episodes of interparental conflict and their temperament. Proximal context, in contrast, refers to the thoughts and feelings experienced by the children immediately before their processing of the conflict episode. This distinction is roughly analogous to that between traits and states. We now consider how distal and proximal context can influence children's interpretation and response to marital conflict.

\section{Distal Context}

A number of distal context factors may affect children's response to marital conflict. Our goal is not to produce an exhaustive list of these but to identify features of the distal context that are likely to be particularly important for understanding why some episodes of conflict are experienced as more stressful than others. Children's past experience with conflict, their construal of the family's emotional climate, temperament, and gender are proposed to affect children's processing and behavior. Each of these factors is briefly described.

Previous experience with conflict. It is hypothesized that past experience with interparental conflict affects children's sensitivity to conflict and creates expectations about the course of conflict episodes. Although we propose that experience with marital conflict is most relevant for children's expectations about future conflict episodes, other types of conflict may also affect children. In particular, previous conflicts between parents and the child and his or her siblings might also influence children's processing of marital conflict. The influence of children's previous experience with conflict is dependent on children's memory; therefore, it might be expected that memories of past conflict would exert more of an effect on children as their memory capabilities increase with age (for a review, see Brown, Bransford, Ferrara, \& Campione, 1983).

The dimensions of conflict episodes that influence children's immediate response to conflict are also proposed to be significant aspects of children's memory of past conflicts. To the extent that previous conflicts have been frequent, intense, and poorly resolved and the content has concerned the child or the marriage, children are likely to anticipate similarly upsetting situations when conflicts recur in the future. In addition, parents' explanations of conflicts in the past may be important. Interparental conflict is likely to be confusing, especially for younger children who may not understand that a person can have both positive and negative feelings for someone. Because young children evidence a tendency to blame themselves for maternal anger (Covell \& Abramovitch, 1987) and marital dissolution (Kurdek, 1986), parents' explanations for conflict are likely to be critical in helping children understand these stressful events. How well children understand their parents' explanation will depend on their level of cognitive development, and 
thus, parents' sensitivity to their children's level of understanding is an important factor in determining the impact of their explanations.

Perceived emotional climate. Perceived emotional climate refers to the child's perception of family relationships, which is based on but not necessarily veridical with their experiences in the family. Garmezy (1983) argued that a warm, supportive family environment serves as a protective factor against stress for children; thus, one would expect that conflict occurring in a such a family is likely to be experienced as less upsetting than conflict in a family that is uncommunicative and emotionally distant. Children may feel more secure in a family that they perceive as warm and cohesive and feel less threatened when conflict occurs.

The quality of parent-child relationships is a major component of the child's perception of the family's emotional climate. Good parent-child relationships provide security for children and may serve to buffer them from a range of stressors, including marital conflict (Emery, 1982; Rutter, 1979). Thus, in addition to having direct effects on children's adjustment, the nature of parent-child relationships may have an indirect effect on children's coping with marital conflict by moderating the stressfulness of particular episodes of conflict.

Temperament. Although there is little direct evidence pertaining to the effects of temperament on children's reaction to stress (Rutter, 1983), children's temperament may affect the relationship between marital conflict and children's adjustment in three ways. First, some children are more reactive to stressors of all kinds (Compas, 1987; Kagan, 1983), and thus may exhibit greater sensitivity to the occurrence of conflict and perhaps more intense affective reactions. Second, temperament also may influence children's behavioral responses (Compas, 1987). For example, children who have a tendency to act aggressively may be more likely to engage in aggressive behaviors when they experience stress. Finally, children's temperament affects the development of parent-child relationships (Rutter, 1979,1983 ), and thus may have an effect on parent-child conflict and the emotional climate of the family.

Hetherington (1989) recently reported data pertaining to the role of temperament in children's adjustment to divorce. She found that the effect of temperament depends on a number of factors, including the personality of the mother, availability of social support, and degree of stress experienced. Temperamentally difficult children tended to exhibit less adaptive behavior than temperamentally easy children only under conditions of high stress or low social and maternal support; when stress was low and support was adequate, "difficult" and "easy" children did not differ in their adjustment to divorce.

The influence of temperament on children's coping with marital conflict may be best understood from a "goodness of fit" perspective (Chess \& Thomas, 1984), which considers both the child's temperament and the parents' responsiveness to the child. For example, a child who is very sensitive to environmental stressors might not be unduly upset by stressful events if his or her parents respond quickly and effectively when such events occur, whereas the same child with less responsive parents might experience greater distress when upsetting events occur. Thus, the "fit" between parents and child may be a more im- portant predictor of the child's response to interparental conflict than either parent or child characteristics alone.

Gender. It is plausible that different socialization experiences may lead to different affective and behavioral responses to conflict in boys and girls. Boys may be less likely to cry or exhibit distress than girls and more likely to act aggressively. As aggression is less tolerated in girls, they may develop alternative approaches to coping with stressful situations. Our review indicates that marital conflict is associated with adjustment problems in both boys and girls, but that some studies have found gender differences in children's immediate response to marital conflict. There is evidence that boys are more likely to respond to conflict between strangers with aggressive behavior and girls with distress (E. M. Cummings et al., 1985, 1989), and that girls generate more competent solutions for such conflicts (E. $M$. Cummings et al., 1989); however, no sex differences have been found in studies investigating children's behavioral response to interparental conflict (E. M. Cummings et al., 1981, 1984). Interestingly, Vuchinich, Emery, and Cassidy (1988) reported that girls tend to intervene more frequently than boys in all types of family conflict except marital conflict.

Although caution must be exercised in interpreting null findings, these studies suggest that gender differences in children's response to conflict are complex. Gender may be related to the affect generated during a conflict episode and to the strategies generated to cope with marital conflict, but may not be related to actual behavior.

\section{Proximal Context}

In contrast to distal context, proximal context can change rapidly as an episode of conflict unfolds because it consists of transient thoughts and feelings experienced by the child immediately before his or her processing of parental behavior. Two proximal factors are hypothesized to be particularly important influences on processing: expectations for the course of conflict and children's current mood.

Expectations for the course of conflict. Expectations are proposed to be a function of both past experience with conflict and the current situation. For example, if a child hears his mother slam the door when she gets home from work, he may infer that she is angry and anticipate that some sort of conflict is imminent. If previous marital conflict has been hostile and poorly resolved, the child may recall this and expect an intense and drawn-out disagreement, and might therefore be primed to experience greater negative affect when the conflict occurs than a child who expects less intense conflict. Conversely, if situational factors or the child's experience with conflict leads him or her to believe that parental conflict is likely to be minor, the child may experience lower levels of distress during the course of the conflict.

Current mood. It is likely that children's mood also may affect their processing of marital conflict (Forgas, Burnham, \& Trimboli, 1988; Masters, Barden, \& Ford, 1979; Masters, Felleman, \& Barden, 1981). For example, a girl having difficulty with homework may feel sad or frustrated, which may lead her to react more intensely to conflict than if she had been enjoying a television show. If children are in a sad or angry mood when 
interparental conflict occurs, they may be more likely to attend to or remember negative aspects of the parental interaction (Bartlett, Burleson, \& Santrock, 1982; Forgas et al., 1988; Nasby \& Yando, 1982). Additionally, negative mood states may facilitate the recall of previous unpleasant events (see Forgas et al, 1988). Therefore, experiencing negative affect before witnessing interparental conflict may exacerbate the stressfulness of the conflict, while positive affect may reduce it. However, if the conflict is very intense or long lasting, the effect of children's current mood may be negligible.

As with the properties of marital conflict, these contextual factors are present simultaneously, and therefore the impact of any one factor must be considered in relation to the others. Moreover, contextual factors may be interrelated. For example, the child's construal of the family climate is likely to reflect the frequency and intensity of conflict as well as the temperament of the child.

We turn now to consider children's processing of the conflict episode, focusing on how children's understanding of conflict may mediate their affective response and coping behavior, and how contextual factors influence processing.

\section{Children's Processing of Conflict}

Interparental conflict can be viewed as prompting three questions for children: "What is happening?" "Why is it happening?" "What can I do about it?" Children's answers to these questions emerge from two proposed stages of processing, termed primary and secondary processing (Bradbury \& Fincham, 1987). Although a number of writers have noted the importance of considering children's perceptions of stressful events (Compas, 1987; Herzberger \& Tennen, 1986; Kagan, 1983), very little research has actually investigated children's cognitive processing of such events. The cognitive factors we include in the framework are derived from research on adults and studies examining children's understanding of divorce. Because children's cognitions are a relatively unexplored aspect of their coping with marital conflict, we discuss primary and secondary processing in some detail.

\section{Primary Processing}

In primary processing the child attends to the conflict and extracts information regarding its negativity, threat, and self-relevance. The child's perception of conflict thus leads to an affective evaluation of the event as threatening or benign (Bretherton et al., 1986). ${ }^{4}$ The distress observed in children witnessing anger between adults (E. M. Cummings \& Cummings, 1988) and the finding that a majority of children report feeling afraid when their parents argue (Peterson \& Zill, 1986) indicate that they perceive potential harm to themselves or others when conflict occurs. Marital conflict, particularly if it is intense, may produce a range of fears in children, including the concern that they will become involved in the conflict, that marital conflict may portend degeneration in parent-child relationships (Wallerstein \& Kelly, 1980), or that conflict may lead to dissolution of the marriage (Bowlby, 1973). Primary processing thus is analgous to what Lazarus and Folkman (1984) termed primary appraisal, which involves an estimation of the threat or challenge presented by a stressor.

There are likely to be individual differences in the affective response that occurs as a function of primary processing. Although most children exhibit signs of distress when exposed to conflict, there is considerable variation in the intensity of expressed negative affect (E. M. Cummings et al, 1981). This may reflect differences in thresholds for attending to conflict resulting from either temperamental or experiential factors. Some children appear to be more sensitive to the environment in general, displaying signs of distress to a wide variety of stimuli (Compas, 1987; Kagan, 1983), and children who have been exposed to more frequent conflict are more reactive when conflict occurs (E. M. Cummings et al., 1981, 1985).

Children's primary processing may be influenced by their developmental level. E. M. Cummings's (1987) finding that preschoolers are more likely than toddlers to attend to angry interchanges between others and to react emotionally suggests that there may be age differences in children's awareness of interparental conflict. E. M. Cummings and Cummings (1988) argued that "relative emotional and cognitive immaturity may interfere with toddlers' ability to process anger" (p. 300). Although young children may feel threatened by an upsetting event like obvious interparental conflict, as children get older they are more able to discern subtle forms of conflict and become more aware of the particular threats posed by marital discord. For example, older children are more able to conceive of the possibility of divorce and appear to be more sensitive to how conflicts are resolved (E. M. Cummings et al, 1989). Because secondary processing requires relatively sophisticated cognitive capabilities, the responses of very young children may reflect only primary processing.

If conflict is not evaluated negatively or considered important, attention may shift away from the conflict and it may cease to affect the child. If the conflict is perceived as negative, significant, or self-relevant, further processing usually will occur. However, there may be circumstances when primary processing leads directly to overt behavior. For example, very young children who have not developed the cognitive capacities integral to secondary processing will be guided by primary processing. Additionally, the arousal resulting from primary processing may preclude or interfere with further cognitive processing (Fincham, Bradbury, \& Grych, 1990), although attempts to understand the conflict may continue once arousal has decreased.

\section{Secondary Processing}

In secondary processing further information is extracted from the situation in an effort to understand and cope wih the

\footnotetext{
${ }^{4}$ In the terms of the relational view of emotion advanced by Campos et al. (1989), primary processing determines the significance of marital conflict to the child. According to this perspective, events are significant-and thus emotionally arousing - when (a) they are relevant to the goals or strivings of the individual, (b) there is emotional communication from significant others, or (c) the event intrinsically produces pain or pleasure.
} 
conflict (Bradbury \& Fincham, 1987). During this stage it is hypothesized that children will try to discover why the conflict is occurring (causal attribution), who is responsible for it (responsibility attribution), and whether they have adequate skills for successfully coping with the conflict (efficacy expectation). Secondary processing is influenced by affect aroused during primary processing (see $A f f e c t$ ), and in turn serves to modulate the child's initial affective response.

Causal attributions. Children's causal attributions have been proposed to be important in coping with divorce (Kurdek, 1986) and abusive treatment by parents (Herzberger \& Tennen, 1986), and they play an important role in children's relations with their peers (e.g., Dodge, 1986; Dodge \& Frame, 1982). Causal attributions serve an adaptive function (Fincham \& Cain, 1986). For example, Compas (1987) noted that analyzing the cause of a stressful event may help children cope with stressors because it helps the child anticipate and prepare for similar episodes in the future. Whether anticipation of future conflict is beneficial, however, will probably depend upon whether children believe that they can cope with the stressor when it occurs.

Causes can be classified on a number of dimensions, but the most widely studied are locus (the degree to which the cause is something about the self, other people, or external circumstances), stability (the degree to which the cause is likely to be present in the future), and globality (the degree to which the cause is seen as affecting other areas of one's life). Attributing negative events to internal, stable, and global factors has been shown to increase their impact (Bradbury \& Fincham, 1990; Peterson \& Seligman, 1984). This suggests that a child who views him or herself as the cause of parental conflict is likely to experience more distress than a child who attributes the cause of conflict to one or both parents or to outside circumstances. Similarly, a child who views conflict as caused by a stable and global factor (e.g., the parents do not love each other) is likely to be more upset by conflict than a child who makes an unstable, specific attribution (e.g, mother is in a bad mood), because it implies that the causes of the conflict are more likely to recur in the future and to affect many areas of family life. The expectation of future family turmoil or dissolution may lead to fear, sadness, or feelings of hopelessness in the child.

Children's attributions for the cause of marital conflict are likely to change developmentally. ${ }^{5}$ Research on the development of causal attributions indicates that preschoolers make causal inferences about events, but that their causal reasoning is limited (see Miller \& Aloise, 1989). They are more adept when reasoning from cause to effect than vice versa, and have little awareness of distal causes of events, such as past behavior or personality. Moreover, even though young children may make stable or global attributions, several studies suggest that they may not realize such attributions have implications for the future (c.g., Allen, Walker, Schroeder, \& Johnson, 1987; R holes \& Ruble, 1984; Rotenberg, 1980). Thus, if young children do not directly observe the proximal cause of conflict, they are likely to have trouble understanding why the conflict is occurring, particularly if the cause involves past events and personality traits. Consequently, they may conclude that some more proximal event, possibly their own behavior, caused the conflict. As children get older, their causal inferences get more sophisti- cated, and they make increasing reference to intentions, thoughts, and dispositions (Shantz, 1983). Older children therefore are more likely to understand the varied factors that lead to marital conflict and make more appropriate causal attributions than are preschoolers.

Children's developing ability to take another's perspective may influence their attributions for marital conflict. Children at an egocentric level of thought may not understand that the conflict could have little to do with them, and may assume that they somchow caused the conflict. One of the few studies investigating children's attributions for parental behavior supports this hypothesis. Covell and Abramovitch (1987) found that 5-and 6-year-old children believed that they were the sole cause of maternal anger, whereas 7- to 9-year-old children were able to identify factors other than themselves, such as other family members and intrafamily events, that could cause anger. Research on children's reasoning about divorce also reveals an age-related increase in children's awareness of causal factors other than themselves (Kurdek, 1986; Wallerstein \& Kelly, 1980). Three- to 5-year-old children tend to believe that they are the cause of their parents' divorce, but older children realize that factors such as parental incompatibility can lead to divorce (Kurdek, 1986). Thus, research on the development of causal attributions suggests that young children may tend to make internal attributions for family events, and may not evidence the association between stable attributions and expectations discussed previously.

Attributions of responsibility and blame. When they have identified the cause of conflict, children may also make judgments regarding whether the causal agent is responsible and should be blamed for the conflict. Responsibility attributions occur once the cause of an event has been established and center on the issue of accountability (Fincham \& Bradbury, in press; see Shaver, 1985). ${ }^{6}$ Attributions of responsibility and blame rest on a number of criteria (e.g., intention, motivation,

\footnotetext{
${ }^{5}$ Although the literature on social cognitive development is extensive, very little research has examined the development of children's perception of family interactions. Most studies in this domain use novel stimuli that are far removed from interactions with parents or siblings, and the extent to which one can generalize from this research to children's perception of interactions that are familiar, often repeated, and affectively charged is open to question. Somc circumstances (e.g., the complexity and familiarity of the event to the child) make it easier for children to make these inferences than others. Because of their familiarity with family members, children may exhibit more sophisticated processing within the family than that reported in studies using novel laboratory stimuli. However, the few studies on children's reasoning about divorce tend to support the conclusions of basic research (see Kurdek, 1986), increasing confidence that these findings are relevant to understanding children's processing of marital conflict.

${ }^{6}$ Although responsibility and blame can be distinguished conceptually (see Fincham \& Bradbury, in press; Shaver, 1985), it is not clear that such distinctions are relevant to children or to attributions in intimate relationships. However, children as young as 6 years do distinguish between cause and blame (see Fincham \& Jaspars, 1979). Thus, the distinction between attributions of responsibility and blame is not maintained, but these attributions are distinguished from causal attributions.
} 
capacity, voluntariness, and control) (see Shaver, 1985). However, some of the criteria used by adults will not be relevant for children. Because they generally view their parents as powerful, children are unlikely to question whether their parents have the capacities required to be held accountable for their actions, whether their behavior was voluntary or under their control. Intent and motivation may be more relevant dimensions. For example, when a girl intervenes in parental conflict and is angrily told to leave the room, the impact on the child may vary depending on whether or not she believes the anger was intentionally targeted at her or was unintentional.

Judgments of blame are proposed to give rise to specific emotions (Fincham et al., 1990). Children who blame themselves for conflict may feel guilty or ashamed, which may also affect their self-esteem. If the parent is blamed for the conflict, anger may result. Feeling angry at a parent may itself create problems for a child because anger may conflict with positive feelings the child has for the parent. Children who do not yet understand that one can feel both positive and negative emotions about another person may be confused or feel guilty about experiencing such conflicting feelings.

Attributions of responsibility and blame also have been shown to change with age. Children as young as 4 years of age can identify adults' intentions for their behavior (Livesley \& Bromley, 1973), but preschoolers tend to overattribute intentionality, seeing all human behavior as intended (Miller \& Aloise, 1989). Thus, preschoolers may believe that parents intend to upset them by arguing. By 5 years of age, children can distinguish between intended and unintended outcomes, although in a less sophisticated way than older children, and tend to judge only voluntary acts as intentional (Shantz, 1983). Young children also exhibit a positivity bias in making inferences about intentionality, which seems to wane in early elementary school (Shantz, 1983): Preschoolers have a tendency to see people as intending to do good things, and not intending to do bad things (Rholes \& Ruble, 1986; Smith, 1978) and attempt to maintain this belief even in the face of conflicting evidence. Because parents are likely to be viewed positively by their children, this bias may make it especially difficult for young children to blame their parents for upsetting events such as marital conflict. Reluctance to hold parents responsible for negative consequences may turn the focus of blame on the child, and Selman's (1980) work on parent-child relations suggests that children's object of blame may change with age. Very young children tend to blame their parents for punishing them, but when they are slightly older they come to believe that their parents are always right, and thus blame themselves if their parents punish them. Later, children acquire a more sophisticated view of the parent-child relationship and understand that one person rarely is wholly to blame for difficulties. Thus, children who are at an age at which they do not blame their parents for negative events may be particularly likely to blame themselves.

Research on children's understanding of divorce has investigated age differences in children's perception of blame, but has produced inconsistent results. Two studies that directly assessed children's blame for the divorce found that children of all ages generally did not assume responsibility for the divorce (Kurdek, Blisk, \& Siesky, 1981; Warshak \& Santrock, 1983). In contrast, Wallerstein and Kelly (1980) found that 3- to 5-yearold children tended to blame themselves for the divorce, and Neal (1983) reported that 5- to 8-year-old children were more likely than 9- to 12-year-old children to view the divorce in personal and egocentric terms and to believe that children could cause particular mother-father interactions.

Efficacy expectations. Children's responses to interparental conflict are also likely to be influenced by their beliefs in their ability to cope with the conflict (Compas, 1987). We distinguish the child's expectations about the course of conflict from his or her efficacy expectations. Whether a child believes a conflict will be intense versus mild or happily resolved versus unhappily resolved is distinct from the child's beliefs about whether he or she can cope with the conflict. Unlike expectations regarding the conflict, efficacy beliefs are proposed to be directly linked to children's affect and behavior. If efficacy expectations are high, children are likely to feel hopeful and to engage in effective coping behaviors. On the other hand, if effcacy expectations are low, hopelessness or helplessness may result, and coping efforts may be diminished.

Efficacy expectations (Bandura, 1982) are proposed to be affected by children's attributions, past coping efforts, and their affective arousal. For example, attributing the cause of conflict to external factors may lead to lower efficacy expectations because it reflects the belief that the cause is outside of the child's control. If children have been successful in decreasing the distress caused by marital conflict, either by stopping the conflict or by regulating their affective reaction, they may be more likely to believe that they can cope with conflict. Although research suggests that children who can generate more numerous coping strategies are more socially competent (Spivak \& Shure, 1982), children who have one strategy that is consistently effective might also have positive expectations about their ability to cope with conflict. Finally, children who perceive greater threat and experience more intense negative affect may feel less able to cope effectively with the conflict than children who feel less threatened by the conflict.

Efficacy expectations regarding perceived ability to cope with parental conflict are also likely to be age related. Young children often exhibit "magical thinking," such as the belief that they have extraordinary powers. Such children may believe that they can stop their parents' conflicts even though they may have little actual success. As children get older, they are likely to have a more realistic appraisal of their ability to affect episodes of interparental conflict. Children also develop more advanced problem-solving skills that may lead to more optimistic expectations about coping successfully with parental conflict. Moreover, increasing cognitive maturity will enable children to take better advantage of their coping repertoire and adapt their skills to situational demands. However, children's efficacy expectations may be more strongly influenced by their past experience with marital conflict than their level of cognitive development. Previous attempts at intervention may lead to greater or lesser optimism in children's ability to change the course of interparental conflict.

Thus far, we have considered the context and processing aspects of the framework. Next, we highlight important aspects of the final two components included in the framework, affect and coping behavior. 


\section{Affect}

In the proposed framework affect is involved in evaluating the significance of the conflict and in guiding subsequent behavior. Observing marital conflict is likely to produce some degree of negative affect in children. Although children exhibit a variety of emotional responses to anger between others, distress and anger are the most common (see E. M. Cummings \& Cummings, 1988). For example, 10- to 20-month-old children responded to anger between family members by expressing anger in $24 \%$ of the incidents, by showing distress in $47 \%$ of all incidents, and with no affective reaction in $23 \%$ of all incidents (E. M. Cummings et al., 1981).

Affect generated by primary processing may influence children's further processing and behavioral response in a number of ways. Affect has been shown to influence children's expectations about future events, attributions, and the generation of coping strategies (see Masters et al., 1981). In adults, negative affect has been shown to lead to attributions that increase the negative impact of life events (Baumgardner \& Arkin, 1988). Negative affect also may interfere with memory for positive events, making it difficult for children to regulate their emotional responses (Nasby \& Yando, 1982). Further, some children may be overwhelmed by their emotional reaction and not engage in secondary processing; in such cases, affect should lead directly to behavioral expression of emotion, such as crying.

Children's cognitive processing of the conflict is also likely to affect the particular emotion children experience. Weiner (1986) found that some attributions reliably evoke certain emotions. For example, attributing failure at a task to internal, stable causes leads to the experience of guilt or shame. Although simply observing marital conflict is likely to produce negative emotions-what Weiner terms outcome-dependent emotions-the type of attribution made by children may also shape their emotional response. For example, if a boy feels upset when conflict occurs and perceives his father as the cause, he may feel angry at his father.

Some data do suggest that the nature and intensity of children's affective response to interparental conflict changes with age. E. M. Cummings et al. (1984) reported that 1 - to $21 / 2$-yearold children were more likely to cry and express anger and excitement when exposed to angry interactions between family members than were 6- to 7-year-olds, a finding that may reflect the increased ability of the older children to regulate their emotional responses. Examining children's reactions to videotaped angry interactions between strangers, E. M. Cummings et al. (1989) reported that the dominant emotional experienced by $6-$ to 7-year-old children was anger, whereas 8- to 9-year-olds were more likely to experience distress. Although age may be related to children's affect, it is likely that children's emotional response to marital conflict will be influenced by a number of factors, including their efforts to cope with the conflict.

\section{Coping Behavior}

Children's coping behavior may take a variety of forms. Folkman and Lazarus (1980) distinguished between two general classes of coping responses: problem-focused and emotion-fo- cused strategies. Both types of strategies, if successful, serve to decrease the emotional arousal caused by the stressful situation. Problem-focused strategies are direct attempts to alter a stressful event, such as children's attempts to intervene in parental conflict. Emotion-focused strategies are attempts to regulate one's emotional response instead of attempting to change the situation. If a child finds that direct interventions are not successful, he or she may try to change their emotional response to parental conflict. Herzberger and Tennen (1986) discussed a number of cognitive strategies children might use to regulate emotion, including attempting to change one's interpretation of the event, focusing on positive aspects of the situation, and retrospective control, which involves holding one's self responsible for the event in an effort to maintain the belief that one can control similar situations in the future.

Children's behavioral response may often change the course of the conflict episode. Attempts to intervene or distract the parents' attention may result in deescalation of conflict or may lead to direct involvement of the children in the conflict. Changes in the conflict situation may then lead to a new sequence of processing. Whatever the result of the behavior, its effectiveness in alleviating the stress associated with marital conflict is likely to affect children's expectations about their ability to cope with future conflict episodes. Further, Emery (1989) noted that successful attempts by the child to intervene in the conflict are likely to be maintained if they are functional for the family system, even though they may be maladaptive for the child. For example, a child may act out to distract his parents from their disagreements, thereby shifting the focus of concern in the family from marital problems to child behavior, a process known as scapegoating.

As children get older, they tend to acquire a wider variety of coping skills and develop a more extensive social support network through their greater involvement with peers (Compas, 1987; Hetherington et al., 1989). Younger children, in contrast, are more dependent upon their parents and more restricted to the home environment. Thus, older children might be expected to have more strategies for coping with interparental conflict at their disposal, although their expectations for the efficacy of these strategies is likely to depend primarily on whether they have been successful in the past.

Older children are more able to engage in particular types of coping behavior. For example, many emotion-focused coping strategies depend on the ability to cognitively restructure the stressful situation, which requires a certain degree of cognitive maturity (Herzberger \& Tennen, 1986). Consistent with this notion, Compas, Malcarne, and Fondacaro (1988) found that eighth graders were able to generate more emotion-focused strategies for coping with stressful events than were sixth or seventh graders. Thus, younger children who do not have the capacity to engage in sophisticated cognitive coping strategies may rely instead on rudimentary strategies such as attempting to escape from the situation. Because young children do not have the autonomy and freedom older children enjoy, however, their efforts to escape may be quite constrained.

To the extent that coping strategies are successful in reducing the emotional upset aroused by interparental conflict, they are likely to be repeated; however, strategies that are successful in interrupting marital conflict may become maladaptive if they 
lead to the child being drawn into the conflict or becoming the focus of family problems (Emery, 1989).

\section{Illustration of the Framework}

To provide a more concrete illustration of how the components and processes just discussed affect children's experience of interparental conflict, we now present an example of a child's exposure to a conflict episode. In the illustration we show how features of the conflict and cognitive, contextual, and developmental factors influence a child's understanding and response to interparental conflict. The example involves Tom, a 6-year-old boy who is the only child in an intact family. Tom's parents are having an argument while he is in an adjoining room where he can hear the conflict clearly. We outline the details of the conflict in the terms of the model, indicating factors that may increase and decrease the impact of the conflict on Tom.

\section{Properties of the Conflict}

Tom's parents are arguing about his father's wish to read the newspaper undisturbed before dinner. Tom hears his mother angrily telling his father that he is selfish and uncaring, and should spend the time before dinner with his son. Tom's father becomes very angry and asserts that he never has time to relax at home, and he wants to be left alone when he gets home from work (content). Although no physical aggression occurs, the conflict is loud and emotional (intensity). The argument continues for $10 \mathrm{~min}$ (duration), and the parents come no closer to resolving their differences (resolution). This conflict is likely to create considerably more distress for Tom than if his parents calmly discussed their differences, had been arguing over something unrelated to him (e.g., work), and had resolved their differences in a mutually satisfying way.

\section{Contextual Factors}

Tom has witnessed many other intense arguments between his parents in the past, but is largely ignored by them at these times (previous experience with conflict). He had unsuccessfully tried to interrupt his parents' fights on a couple of occasions. Although Tom has a reasonably good relationship with his mother, he is not close to his father and sometimes wonders how much his father cares for him. Tom does not see his parents express much warmth toward each other (perceived emotional climate). Tom is somewhat easily upset by stressful events, but is not particularly aggressive (temperament). When the current episode of conflict began, Tom had been in an anxious mood because he knows that his parents often get into fights when his father comes home, and was expecting another angry confrontation today (proximal context).

This particular constellation of factors is likely to lead to more distress than if previous conflicts had been less frequent or intense, or if they had been happily resolved. Tom's emotional response also might be attenuated if he were in a relaxed or calm mood when the conflict began. Finally, if Tom experienced closer family relationships he might feel less threatened by the conflict and feel assured that his father loved him even though he did not want to play with him until after dinner.

\section{Processing of the Conflict and Coping Response}

Tom attends to the conflict (primary processing) and hears his mother accusing his father of not spending enough time with him, and his father saying that he does not want to be bothered by Tom right after coming home from work (high negativity, threat, and self-relevance). Tom feels scared and saddened by the conflict (primary affective response) and concludes that he is the source of the conflict since he does ask to play with his father when he arrives home (causal attribution). He blames himself for the conflict (responsibility attribution), which produces feelings of guilt and leads to even greater dejection. Tom feels helpless to stop his parents' argument (efficacy expectation) and does not try to intervene. Instead, he stays in the adjoining room and puts his hands over his ears in an unsuccessful effort to shut out the sound of the conflict (coping behavior).

Tom's response to the conflict might have been different had his processing of the conflict been different. Although he might have been upset simply because his parents were fighting, had he attributed the fight to his father's fatigue and judged that no one was really to blame for the fight, he might not have felt as sad or guilty. Further, if Tom believed that he could help resolve the conflict by going into the room and discussing the cause of the conflict with his parents, perhaps he would have felt more confident in his ability to cope with the conflict and chosen a more effective strategy.

Depending on Tom's level of development, many of the processes described previously might be different. For example, an older child might be less likely to perceive himself as the cause of the conflict and to blame himself for its occurrence. Instead, he may attribute the conflict to his father's personality or a bad day at work, attributions that are less likely to have an impact on his self-esteem. On the other hand, older children's capacity for hypothetical thought allows them to consider future implications of marital conflict. For example, if Tom believes that the cause of marital conflict is stable and global (e.g., his parents are incompatible), he may fear that his parents will divorce. An older child also might be better able to cope with his parents' arguments. Although he may not be able to stop the conflict, he may use an emotion-focused strategy that decreases its negative impact, or he might leave the house and find friends to spend time with. Having applied our framework to a concrete example of marital conflict, we turn to explore its implications for children's adjustment.

\section{Implications of the Framework for Children's Adjustment}

Although it is clear that many children exhibit fear, distress, or anger when observing hostile interactions between their parents (E. M. Cummings et al, 1981, 1984), only a single study has linked these immediate reactions to behavior problems (E. M. Cummings et al., 1989). Considerable work is needed to investigate how the processes that occur when children observe marital conflict affect their adjustment. We believe that the frame- 
work outlined suggests a number of avenues by which the experience of interparental conflict may lead to problems for children. In addition to the mechanisms already proposed to explain how exposure to conflict can lead to child problems (e.g., modeling, stress), dysfunctional attributions and the development of maladaptive coping strategies may also be important mechanisms.

A tendency to make particular types of attributions for marital conflict may lead to problems for children. Stable and global attributions may lead to an expectation of continued interparental conflict, which may result in sadness, anger, or feelings of hopelessness. Children who tend to perceive themselves as the cause of marital conflict or blame themselves for conflict may suffer decrements in self-esteem. Consistent with this hypothesis, children who make external, unstable attributions for abusive parental treatment are proposed to be less likely to suffer harm to their self-esteem (Herzberger \& Tennen, 1986), and Brewin (1986) argued that low self-esteem accompanying depression results from self-evaluation or selfblame. Younger children may be more likely to blame themselves for stressful family events than older children, who are better able to understand the parents' causal role and the intended and unintended effects of marital conflict. In addition to the potential impact on their sense of self-worth, children's attributions of responsibility and blame for marital conflict may also affect their conceptions of their parents. For example, blaming a parent for conflict that upsets the child or the other parent may affect a child's relationship with that parent, particularly if the parent is viewed as willfully hurting the other parent or the child.

E. M. Cummings and Cummings (1988) speculated that observing parental anger may lead to adjustment problems by promoting the development of maladaptive coping strategies. Although it may be adaptive for children to act out to distract attention from the marital conflict or to withdraw when their parents fight, similar behavior outside of the family can be problematic. For cxample, children who aggress or withdraw from interaction with peers when conflicts of interest arise may have difficulty in peer relations. The ability to manage conflict is an important component of successful interaction for children of all ages (Parker \& Gottman, in press). Additionally, frequent exposure to anger may promote the development of coping styles that make the child extremely sensitive to the occurrence of conflict, and may lead children to overreact when conflict occurs or to perceive conflict in ambiguous situations (E. M. Cummings \& Cummings, 1988). Children who witness a great deal of hostility at home may come to perceive hostile intent in otherwise ambiguous situations, and respond in an inappropriately aggressive manner. Responding in this way to ambiguous situations may then foster aggressive responses in others, and result in more frequent experience of conflict in a variety of contexts (Dodge, 1986).

The extent and type of adjustment problems associated with marital conflict may differ depending on the developmental task faced by the child. For example, an important task for children first entering school is to establish friendships with other children, and aggressive or withdrawn behavior may make it difficult for them to get along with others. Similar behavior at a later age, when children have already established a consistent peer network, might have less effect on interactions with pecrs. Children who are rejected by their peers are at risk for a host of negative outcomes later in life (for a review, see Parker \& Asher, 1987), and so factors that interfere with good peer relations warrant concern. Further, the effects of exposure to a high level of interparental conflict might be compounded if other life stressors are occurring at the same time. Rutter (1979) found that a small increase in the number of stressors experienced by children greatly increases their risk for adjustment problems, and therefore children who are experiencing normative, age-linked stressors such as changing schools may be more affected by the stress associated with interparental conflict.

Examining the processes that occur when children witness interparental conflict may reveal unexplored mechanisms by which conflict leads to adjustment problems. The framework we offer proposes that children's understanding of conflict and strategies for coping with conflict may be linked to later problems, and highlights the importance of considering the child's developmental level when investigating the effects of marital conflict. In addition to suggesting paths by which interparental conflict may lead to adjustment problems, this framework points to other promising avenues for future research.

We believe that a more complete account of the relationship between marital conflict and children's adjustment will be gained by considering five issues. First, as noted at several points in the present article, a primary task for future research is the investigation of the factors and processes that mediate the immediate impact of marital conflict on children. Our framework focuses on the role of children's cognitions and experiences with conflict, but children's ability to regulate their emotional arousal and parental beliefs about conflict and behavior toward their children when conflict occurs are also likely to be important factors. Once processes that mediate the stressfulness of marital conflict have been identified, the next step is to explore how these processes are linked to more general adjustment problems.

Second, more precise hypotheses concerning the effect of marital conflict on children need to be formulated and tested, a goal compatible with a focus on more microanalytic processes. For more specific hypotheses to be tested, measurement of the constructs of interest must similarly become more precise. It is important to develop more detailed assessments of the dimensions of conflict and a broader range of indexes of children's adjustment. Although it is valuable to assess externalizing and internalizing problems, attention to peer relations, self-esteem, and social competence may provide a more complete picture of children's adjustment. The use of teachers, peers, and the children themselves as raters in this endeavor not only produces independent data but provides unique perspectives on children's functioning both in and outside of the home.

Third, it is important to determine if exposure to marital conflict has long-term consequences for children. Although litthe attention has been paid to such enduring effects, indirect evidence suggests that they may exist. Some children continue to be affected by child abuse (c.g., Amsterdam, Brill, Bell, \& Edwards, 1979; Kinard, 1979) and divorce (Kelly, 1988) years after the events have occurred, an outcome that could result from early learning that affects the availability of response alternatives to children and their views of what is acceptable be- 
havior. In support of this idea, Herzberger and Tennen (1985) found that adults who had experienced severe parental discipline as children viewed severe disciplinary techniques as more appropriate and less severe than did people who had not received such discipline as children. Further, they attributed greater responsibility to the child for the parent's discipline. This study indicates that children can acquire maladaptive attitudes and behaviors from their parents that continue to affect their lives even as adults.

Fourth, the relationship between marital conflict and child behavior problems needs to be examined in relation to other potentially relevant family variables, particularly parent-child relationships. Because some researchers have argued that the effect of marital conflict can be attributed to changes in parent-child relationships (e.g., Jouriles et al., 1987; O'Leary \& Emery, 1984), assessment of both parent-child relationships and marital conflict provides an opportunity to examine the relative effects of these variables. Examining conflict within the broader context of family interactions will provide a more complete picture of the processes that give rise to adjustment problems in children.

Fifth, longitudinal research is necessary to investigate causal effects of marital conflict and the relationship between conflict, family interactions, and children's adjustment over time. Most studies obtain concurrent measures of conflict and behavior problems, leaving unanswered questions pertaining to the effects of the duration of marital conflict on children's adjustment, how children cope with conflict over time, and the impact of continued exposure to conflict. Studies of divorce reveal that behavior problems decrease as conflict decreases, but most of these studies focus exclusively on problem behaviors and do not examine other long-term effects (for an exception, see Hetherington et al., 1982).

\section{CONCLUSION}

Our review documents the existence of a relation between marital conflict and children's adjustment. However, little is known about the processes that give rise to this association. We therefore have offered a framework that integrates findings from this literature and identifies a number of factors that may mediate the impact of marital conflict on children. The framework proposes that the effect of conflict depends on children's understanding of the conflict, which varies as a function of characteristics of the conflict, contextual factors, and level of cognitive development. By placing children's observation of marital conflict in a broader context that includes the perceived emotional climate of the family, their previous experience with conflict, their interpretation of conflict, and their coping ability, we have attempted to lay the foundation for a more complete understanding of the relationship between marital conflict and children's adjustment.

\section{References}

Achenbach, T. M., \& Edelbrock, C. (1983). Manual for the Child Behavior Checklist and Revised Child Behavior Profile. Burlington, VT: University Associates in Psychiatry.

Achenbach, T. M., McConoughy, S. H., \& Howell, C. T. (1987). Child/ adolescent behavioral and emotional problems: Implications of cross-informant correlations for situational specificity. Psychological Bulletin, 101, 213-232.

Allen, J. L., Walker, L. D., Schroeder, D. A., \& Johnson, D. E. (1987). Attributions and attribution-behavior relations: The effect of level of cognitive development. Journal of Personality and Social Psychology, $52,1099-1109$.

Amsterdam, B., Brill, M., Bell, N., \& Edwards, D. (1979). Coping with abuse: Adolescents' views. Victimology, 4, 278-284.

Bandura, A. (1973). Aggression: A social learning approach. Englewood Cliffs, NJ: Prentice-Hall.

Bandura, A. (1977). Social learning theory. Englewood Cliffs, NJ: Prentice-Hall.

Bandura, A. (1982). Self-efficacy mechanism in human agency. American Psychologist, 37, 122-147.

Bandura, A. (1989). Social cognitive theory. In R. Vasta (Ed.), Annals of child development (Vol. 6, pp. 1-60). Greenwich, CT: JAI Press.

Bartlett, J. C., Burleson, G., \& Santrock, J. W. (1982). Emotional mood and memory in young children. Journal of Experimental Child Psychology, 34, 59-76.

Baumgardner, A. H., \& Arkin, R. M. (1988). Affective state mediates attributions for success and failure. Motivation and Emotion, 12, 99106.

Bell, R. Q. (1979). Parent, child, and reciprocal influence. American Psychologist, 34, 821-826.

Belsky, J. (1981). Early human experience: A family perspective. Developmental Psychology, 17, 3-23.

Block, J. H., Block, J., \& Morrison, A. (1981). Parental agreement-disagreement on child-rearing orientations and gender-related personality correlates in children. Child Development, 52, 965-974.

Bowlby, J. (1973). Attachment and loss: Vol. 2. Separation. New York: Basic Books.

Bradbury, T. N., \& Fincham, F. D. (1987). Affect and cognition in close relationships: Towards an integrative model. Cognition and Emotion, 1, 59-87.

Bradbury, T. N., \& Fincham, F. D. (1989). Behavior and satisfaction in marriage: Prospective mediating processes. Review of Personality and Social Psychology, 10, 119-143.

Bradbury, T. N., \& Fincham, F. D. (1990). Attributions in marriage: Review and critique. Psychological Bulletin, 107, 3-33.

Bretherton, I., Fritz, J., Zahn-Waxler, C., \& Ridgeway, D. (1986). Learning to talk about emotions: A functionalist perspective. Child Development, 57, 529-548.

Brewin, C. R. (1986). Internal attributions as moderator variables within social interactional systems. Cognitive Therapy and Research, $10,469-475$.

Brody, G. H., \& Forehand, R. (1986). Maternal perceptions of child maladjustment as a function of the combined influence of child behavior and maternal depression. Journal of Consulting and Clinical Psychology, 54, 237-240.

Brody, G. H., Pillegrini, A. D., \& Siegal, I. E. (1986). Marital quality and mother-child and father-child interactions with school-aged children. Developmental Psychology, 22, 291-296.

Brown, A. L., Bransford, J. D., Ferrara, R. A., \& Campione, J. C. (1983). Learning, remembering, and understanding. In J. H. Flavell \& H. M. Markman (Eds.), Mandbook of child psychology, Vol. 3: Cognitive development (pp. 77-166). New York: Wiley.

Campos, J. J., Campos, R. G., \& Barrett, K. (1989). Emergent themes in the study of emotional development and emotional regulation. Developmental Psychology, 25, 394-402.

Chess, S., \& Thomas, A. (1984). Origins and evolution of behavior disorders: Infancy to early adult life. New York: Brunner/Mazel.

Compas, B. E. (1987). Coping with stress during child hood and adolescence. Psychological Bulletin, 101, 393-403. 
Compas, B. E., Malcarne, V. L., \& Fondacaro, K. M. (1988). Coping with stressful events in older children and young adolescents. Journal of Consulting and Clinical Psychology, 56, 405-411.

Covell, K., \& Abramovitch, R. (1987). Understanding emotion in the family: Children's and parents' attributions of happiness, sadness, and anger. Child Development, 58, 985-991.

Crockenberg, S. (1985). Toddlers' reactions to maternal anger. MerrillPalmer Quarterly, 31, 361-373.

Cummings, E. M. (1987). Coping with background anger in early childhood. Child Development, 58, 976-984.

Cummings, E. M., \& Cummings, J. S. (1988). A process-oriented approach to children's coping with adults' angry behavior. Developmental Review; 8, 296-321.

Cummings, E. M., Iannotti, R. J., \& Zahn-Waxler, C. (1985). Influence of conflict between adults on the emotions and aggression of young children. Developmental Psychology, 21, 495-507.

Cummings, E. M., Vogel, D., Cummings, J. S. \& El-Sheikh, M. (1989). Children's responses to different forms of expression of anger between adults. Child Development, 60, 1392-1404.

Cummings, E. M., Zahn-Waxler, C., \& Radke-Yarrow, M. (1981). Young children's responses to expressions of anger and affection by others in the family. Child Development, 52, 1274-1281.

Cummings, E. M., Zahn-Waxler, C., \& Radke-Yarrow, M. (1984). Developmental changes in children's reactions to anger in the home. Journal of Child Psychology and Psychiatry, 25, 63-74.

Cummings, J. S., Pellegrini, D. S., Notarius, C. I., \& Cummings, E. M. (1989). Children's responses to angry adult behavior as a function of marital distress and history of interparent hostility. Child Development, 60, 1035-1043.

Dodge, K. A. (1986). A social information processing model of social competence in children. In M. Perlmutter (Ed.), The Eighteenth Annual Minnesota Symposium on Child Psychology (pp. 77-125). Hillsdale, NJ: Erlbaum.

Dodge, K. A., \& Frame, C. L. (1982). Social cognitive biases and deficits in aggressive boys. Child Development, 53, 620-635.

Dunn, J., \& Munn, P. (1985). Becoming a family member: Family conflict and the development of social understanding in the second year. Child Development, 56, 480-492.

Dweck, C. D, \& Leggett, E. L. (1988). A social-cognitive approach to motivation and personality. Psychological Review, 95, 256-273.

Emery, R. E. (1982). Interparental conflict and the children of discord and divorce. Psychological Bulletin, 92, 310-330.

Emery, R. E. (1988). Marriage, divorce, and children's adjustment. Newbury Park, CA: Sage.

Emery, R. E. (1989). Family violence. American Psychologist, 44, $321-$ 328.

Emery, R. E., Joyce, S. A., \& Fincham, F. D. (1987). Assessment of child and marital problems. In K. D. O'Leary (Ed), Assessment of marital discord (pp. 223-261). Hillsdale, NJ: Erlbaum.

Emery, R. E., \& O'Leary, K. D. (1982). Children's perceptions of marital discord and behavior problems of boys and girls. Journal of $A b$ normal Child Psychology, 10, 11-24.

Emery, R. E., \& O'Leary, K. D. (1984). Marital discord and child behavior problems in a nonclinic sample. Journal of Abnormal Child Psychology, 12, 411-420.

Enos, D. M., \& Handal, P. J. (1986). The relation of parental marital status and perceived family conflict to adjustment in white adolescents. Journal of Consulting and Clinical Psychology, 54, 820-824.

Farber, S., Felner, R. D., \& Primavera, J. (1985). Parental separation/divorce and adolescents: An examination of factors mediating adaptation. American Journal of Community Psychology, 13, 171-185.

Feshbach, S. (1970). Aggression. In P. H. Mussen (Ed.), Carmichael's manual of child psychology, Vol. 2. (pp. 159-260). New York: Wiley.

Fincham, F. D., \& Bradbury, T. N. (in press). Cognition in marriage: A program of research on attributions. In D. Perlman \& W. Jones (Eds.), Advances in personal relationships (Vol. 2). Greenwich, CT: JAI Press.

Fincham, F. D., Bradbury, T. N., \& Grych, J. H. (1990). Conflict in close relationships: The role of intrapersonal phenomena. In S. Graham \& V. Folkes (Eds.), Attribution theory: Applications to achievement, mental health. and interpersonal conflict (pp. 161-184). Hillsdale, NJ: Erlbaum.

Fincham, F. D., \& Cain, K. M. (1986). Learned helplessness in humans: A developmental analysis. Developmental Review: 6, 301-333.

Fincham, F. D. \& Jaspars, J. M. (1979). Attribution of responsibility to self and other in children and adults. Journal of Personality and Social Psychology, 37, 1589-1602.

Folkman, S., \& Lazarus, R. S. (1980). An analysis of coping in a middleaged community sample. Journal of Health and Social Behavior, 21, 219-239.

Forehand, R., Long, N., Brody, G. H., \& Fauber, R. (1986). Home predictors of young adolescents' school behavior and academic performance. Child Development, 57, 1528-1533.

Forgas, J. P., Burnham, D. K., \& Trimboli, C. (1988). Mood, memory, and social judgments in children. Journal of Personality and Social Psychology, 54, 697-703.

Garmezy, N. (1983). Stressors of childhood. In N. Garmezy \& M. Rutter (Eds.), Stress, coping, and development in children (pp. 43-84). New York: McGraw-Hill.

Glick, P. C., \& Lin, S. (1986). Recent changes in divorce and remarriage. Journal of Marriage and the Family, 48, 737-747.

Goldberg, W. A., \& Easterbrooks, M. A. (1984). Role of marital quality in toddler development. Developmental Psichology, 20, 504-514.

Griest, D. L., Wells, K. C., \& Forehand, R. (1979). An examination of predictors of maternal perceptions of maladjustment in clinic-referred children. Journal of Abnormal Psychology, 88, 277-281.

Herzberger, S. D., \& Tennen, H. (1985). The effect of self-relevance on judgments of moderate and severe disciplinary encounters. Journal of Marriage and the Family, 47, 311-318.

Herzberger, S. D., \& Tennen, H. (1986). Coping with abuse: Children's perspectives on their abusive treatment. In R. D. Ashmore \& D. M. Brodzinsky (Eds.), Thinking about the family: Views of parents and children (pp. 277-300). Hillsdale, NJ: Erlbaum.

Hess, R. D., \& Camara, K. A. (1979). Post-divorce family relationships as mediating factors in the consequences of divorce for children. Journal of Social Issues, 35, 79-98.

Hetherington, E. M. (1979). Divorce: A child's perspective. American Psychologist, 34, 851-858

Hetherington, E. M. (1984). Stress and coping in children and families. In A. Doyle, D. Gold, \& D. Moskowitz (Eds.), Children in families under stress (pp. 7-33). San Francisco: Jossey-Bass.

Hetherington, E. M. (1989). Coping with family transitions: Winners, losers, and survivors. Child Development, 60, 1-14.

Hetherington, E. M., Cox, M., \& Cox, R. (1982). Effects of divorce on parents and children. In M. E. Lamb (Ed.), Nontraditional families: Parenting and child development (pp. 233-288). Hillsdale, NJ: Erlbaum.

Hetherington, E. M., Stanley-Hagen, M., \& Anderson, E. R. (1989). Marital transitions: A child's perspective. American Psychologist, 44, 303-312.

Jacobson, D. S. (1978). The impact of marital separation/divorce on children: II. Interparent hostility and child adjustment. Journal of Divorce, 2, 3-19.

Johnson, P. L., \& O'Leary, K. D. (1987), Parental behavior patterns and conduct disorders in girls. Journal of Abnormal Child Psychology, 15 . $573-581$.

Johnson, S. M., \& Lobitz, G. K. (1974). The personal and marital ad- 
justment of parents as related to observed child deviance and parenting behaviors. Journal of Abnormal Child Psychology, 2. 193-207.

Johnston, J. R., Gonzalez, R., \& Campbell, L. E. (1987). Ongoing postdivorce conflict and child disturbance. Journal of Abnormal Child Psychology, 15, 497-509.

Jouriles, E. N.. Barling, J., \& O'Leary, K. D. (1987). Predicting child behavior problems in maritally violent families. Journal of Abnormal Child Psychology, 15, 165-173.

Jouriles, E. N., Murphy, C. M., \& O'Leary, K. D. (1989). Interspousal aggression, marital discord, and child problems. Journal of Consulting and Clinical Psychology, 57, 453-455.

Jouriles, E. N., Pfiffner, L. J., \& O'Leary, S. G. (1988). Marital conflict, parenting, and toddler conduct problems. Journal of Abnormal Child Psychology: 16, 197-206.

Kagan, J. (1983). Stress and coping in early development. In N. Garmezy \& M. Rutter (Eds.), Stress, coping, and development in children (pp. 191-216). New York: McGraw-Hill.

Kelly, J. B. (1988). Longer-term adjustment in children of divorce: Converging findings and implications for practice. Journal of Family Psychology, 2, 119-140.

Kinard, E. M. (1979). The psychological consequences of abuse for the child. Journal of Social Issues, 35, 82-100.

Kurdek, L. A. (1986). Children's reasoning about parental divorce. In R. D. Ashmore \& D. M. Brodzinsky (Eds.), Thinking about the family: Views of parents and children (pp. 233-276). Hillsdale, NJ: Erlbaum.

Kurdek, L. A., Blisk, D., \& Siesky, A. E. (1981). Correlates of children's long-term adjustment to their parents' divorce. Developmental Psychology, 17, 565-579.

Lazarus, R. S., \& Folkman, S. (1984). Stress, appraisal, and coping. New York: Springer.

Livesley, W. J., \& Bromly, D. B. (1973). Person perception in childhood and adolescence. London: Wiley.

Long, N., \& Forehand, R. (1987). The effects of parental divorce and parental conflict on children: An overview. Developmental and Behavioral Pediatrics, 8, 292-296.

Long, N., Forehand, R., Fauber, R., \& Brody, G. (1987). Self-perceived and independently observed competence of young adolescents as a function of parental marital conflict and recent divorce. Journal of Abnormal Child Psychology, 15, 15-27.

Long, N., Slater, E., Forehand, R., \& Fauber, R. (1988). Continued high or reduced interparental conflict following divorce: Relation to young adolescent adjustment. Journal of Consulting and Clinical Psychology, 56, 467-469.

Margolin, G. (1981). The reciprocal relationship between marital and child problems. In J. P. Vincent (Ed.), Advances in family intervention, assessment, and theory, Vol. 2 (pp. 131-182). Greenwich, CT: JAI Press.

Masters, J. C., Barden, R. C., \& Ford, M. E. (1979). Affective states, expressive behavior, and learning in children. Journal of Personality and Social Psychology, 37, 380-390.

Masters, J. C., Felleman, E. S., \& Barden, R. C. (1981). Experimental studies of affective states in children. In B. Lahey \& A. E. Kazdin (Eds.), Advances in clinical child psychology (Vol. 4, pp. 91-118). New York: Plenum.

Miller, P. H., \& Aloise, P. A. (1989). Young children's understanding of the psychological causes of behavior: A review. Child Development. $60,257-285$.

Nasby, W., \& Yando, R. (1982). Selective encoding and retrieval of affectively valent information: Two cognitive consequences of children's mood states. Journal of Personality and Social Psychology, 43. 12441253.

Neal, J. H. (1983). Children's understanding of their parents' divorce.
In L. A. Kurdek (Ed.), Children and divorce (pp. 3-14). San Francisco: Jossey-Bass.

O'Leary, K. D., \& Emery, R. E. (1984). Marital discord and child behavior problems. In M. D. Levine \& P. Satz (Eds.), Developmental variation and dysfunction (pp. 345-364). New York: Academic Press.

Oltmanns, T. F., Broderick, J. E., \& O'Leary, K. D. (1977). Marital adjustment and the efficacy of behavior therapy with children. Journal of Consulting and Clinical Psychology, 45, 724-729.

Parker, J. G., \& Asher, S. R. (1987). Peer relations and later personal adjustment: Are low-accepted children at risk? Psychological Bullelin, 102, 357-389.

Parker, J. G., \& Gottman, J. M. (in press). Social and emotional development in a relational context: Friendship interaction from early childhood to adolescence. In T. J. Berndt \& G. W. Ladd (Eds.), Peer relationships in child development. New York: Wiley.

Patterson, G. R. (1977). Accelerating stimuli for two classes of coercive behaviors. Journal of Abnormal Child Psychology, 5, 335-350.

Patterson, G. R. (1986). Performance models for antisocial boys. American Psychologist, 41, 432-444.

Patterson, G. R., \& Stouthamer-Loeber, M. (1984). The correlation of family management practices and delinquency. Child Development, 55, 1299-1307.

Peterson, C., \& Seligman, M. E. P. (1984). Causal explanations as a risk factor for depression: Theory and evidence. Psychological Review, 91, 347-374

Peterson, J. L., \& Zill, N. (1986). Marital disruption, parent-child relationships, and behavior problems in children. Journal of Marriage and the Family, 48, 295-307.

Phares, V., Compas, B. E., \& Howell, D. C. (1989). Perspectives on child behavior problems: Comparison of children's self-reports with parent and teacher reports. Psychological Assessment: A Journal of Consulting and Clinical Psychology, 1, 68-71.

Porter, B., \& O'Leary, K. D. (1980). Marital discord and childhood behavior problems. Journal of Abnormal Child Psychology, 8, 287295.

Quay, H. C. (1977). Measuring dimensions of deviant behaviors: The Behavior Problem Check list. Journal of Abnormal Child Psychology, 5, 277-287.

Rholes, W. S., \& Ruble, D. N. (1984). Children's understanding of dispositional characteristics of others. Child Development, 55, 550-560.

Rholes, W. S., \& Ruble, D. N. (1986). Children's impressions of other persons: The effects of temporal separation of behavioral information. Child Development, 57, 872-878.

Rotenberg, K. J. (1980). Children's use of intentionality in judgments of character and disposition. Child Development, 51, 282-284.

Rutter, M. (1979). Maternal deprivation, 1972-1978: New findings, new concepts, new approaches. Child Development, 50, 283-305.

Rutter, M. (1983). Stress, coping, and development: Some issues and some questions. In N. Garmezy \& M. Rutter (Eds.), Stress, coping, and development in children (pp. 1-41). New York: McGraw-Hill.

Rutter, M., Yule, B., Quinton, D, Rowlands, O, Yule, W., \& Berger, M. (1974). Attainment and adjustment in two geographical areas: III. Some factors accounting for area differences. British Journal of Psychiatry, $125,520-533$.

Selman, R. L. (1980). The growth of interpersonal understanding. New York: Academic Press.

Shantz, C. U. (1983). Social cognition. In J. Flavell \& E. Markman (Eds.), Handbook of child psychology, vol. 3: Cognitive development (pp. 495-555). New York: Wiley.

Shaver, K. G. (1985). The attribution of blame: Causality, responsibility, and blameworthiness. New York: Springer-Verlag.

Shaw, D. S. \& Emery, R. E. (1987). Parental conflict and other correlates of the adjustment of school-age children whose parents have separated. Journal of Abnormal Child Psychology, 15, 269-281. 
Slater, E. J., \& Haber, J. D. (1984). Adolescent adjustment following divorce as a function of familial conflict. Journal of Consulting and Clinical Psychology, 52, 920-921.

Smith, M. C. (1978). Cognizing the behavior stream: The recognition of intentional action. Child Development, 49, 736-743.

Snyder, D., Klein, M. A., Gdowski, C. L., Faulstich, C., \& LaCombe, J. (1988). Generalized dysfunction in clinic and nonclinic families: A comparative analysis. Journal of Abnormal Child Psychology, 16, 97109.

Spielberger, C. (1979). Understanding stress and anxiety. New York: Harper \& Row.

Spivak, G., \& Shure, M. B. (1982). Interpersonal problem solving and clinical theory. In B. Lahey \& A. E. Kazdin (Eds.), Advances in child clinical psychology (Vol. 5, pp. 323-372). New York: Plenum Press.

Sroufe, L. A. (1979). Socioemotional development. In J. Osofsky (Ed.), Handbook of infant development (pp. 462-516). New York: Wiley.

Stoneman, Z., Brody, G. H., \& Burke, M. (1989). Marital quality, depression, and inconsistent parenting: Relationship with observed mother-child conflict. American Journal of Orthopsychiatry, 59, $105-117$.

Straus, M. A. (1979). Measuring intrafamily conflict and violence: The conflict tactics (CT) scales. Journal of Marriage and the Family, 41, $75-88$.

Tennen, H., Affleck, G., Allen, D., McGrade, B., \& Ratzan, S. (1984). Causal attributions and coping in juvenile diabetes. Basic and Applied Social Psychology, 5, 131-142.

Tschann, J. M., Johnston, J. R., Kline, M., \& Wallerstein (1989). Family process and children's functioning after divorce. Journal of Marriage and the Family, 51, 431-444.

Vuchinich, S., Emery, R. E., \& Cassidy, J. (1988). Family members as third parties in dyadic family conflict: Strategies, alliances, and outcomes. Child Development, 59, 1293-1302.

Wallerstein, J. S., \& Kelly, J. (1980). Surviving the breakup: How children and parents cope with divorce. New York: Basic Books.

Warshak, R. A., \& Santrock, J. W. (1983). The impact of divorce in father-custody and mother-custody homes: The child's perspective. In L. A. Kurdek (Ed.), Children and divorce (pp. 29-46). San Francisco: Jossey-Bass.

Waters, E., Jouriles, E. N., Smith, D. A., \& Richters, J. E. (1988). Marital discord and child behavior: A procedural note. Unpublished manuscript, State University of New York at Stony Brook.

Webster-Stratton, C. (1988). Mothers' and fathers' perceptions of child deviance: Roles of parent and child behaviors and parent adjustment. Journal of Consulting and Clinical Psychology, 56, 990-915.

Weiner, B. (1986). An attributional theory of motivation and emotion. New York: Springer-Verlag.

Whitehead, L. (1979). Sex differences in children's responses to family stress. Journal of Child Psychology and Psychiatry, 20, 247-254.

Wierson, M., Forehand, R., \& McCombs, A. (1988). The relationship of early adolescent functioning to parent-reported and adolescent-perceived interparental conflict. Journal of Abnormal Child Psychology, 16, 707-718.

Wolfe, D. A., Jaffe, P., Wilson, S. K., \& Zak, L. (1985). Children of battered women: The relation of child behavior to family violence and maternal stress. Journal of Consulting and Clinical Psychology, $53,657-665$.

Zaslow, M. J. (1988). Sex differences in children's response to parental divorce: 1 . Research methodology and postdivorce family form. American Journal of Orthopsychiatry, 58, 355-378.

Zaslow, M. J. (1989). Sex differences in children's response to parental divorce: 2. Samples, variables, ages, and sources. American Journal of Orthopsychiatry, 59, 118-141.

Zaslow, M. J., \& Hayes, C. D. (1986). Sex differences in children's response to psychosocial stress: Toward a cross-context analysis. In M. E. Lamb, A. L. Brown, \& B. Rogoff (Eds.), Advances in developmental psychology, vol. 4 (pp. 285-337). Hillsdale, NJ: Erlbaum.

Received July 1 1, 1989

Revision received December 4, 1989

Accepted December 22, 1989

\section{Sternberg Appointed Editor of Psychological Bulletin, 1991-1996}

The Publications and Communications Board of the American Psychological Association announces the appointment of Robert J. Sternberg, Yale University, as editor of Psychological Bulletin for a 6-year term beginning in 1991. Beginning immediately, manuscripts should be directed to

Robert J. Sternberg

Yale University

Department of Psychology

P.O. Box 11A Yale Station

New Haven, Connecticut 06520-7447 